\title{
Refined Approaches for Estimating the Strength of Rock Blocks
}

\author{
Anastasios Stavrou - Ioannis Vazaios - William Murphy • Nicholas Vlachopoulos
}

Received: 4 March 2019/Accepted: 15 June 2019/Published online: 24 June 2019

(C) The Author(s) 2019

\begin{abstract}
Micro-discrete fracture networks ( $\mu$ DFNs) have been integrated into grain-based models (GBMs) within the numerical software UDEC to assess rock block strength through a series of unconfined compressive strength (UCS) tests of progressively larger in size numerical specimens. GBMs were generated by utilizing a Voronoi tessellation scheme to capture the crack evolution processes within the intact rock material, and $\mu \mathrm{DFNs}$ were separately created and embedded into the GBMs to simulate the effect of preexisting defects. Various $\mu \mathrm{DFN}$ s realisations were generated stochastically within the software FracMan to assess the combined impact of defect intensity, persistence, strength and specimen size. The resulting synthetic rock block models were used to assess the "flawed" material strength at block scale through a rigorous sensitivity numerical analysis. The acquired results predict a progressive strength reduction with decreasing intact rock quality and certain trends are captured when rock block strength is expressed as a
\end{abstract}

A. Stavrou $(\bowtie) \cdot$ I. Vazaios

Arup, 13 Fitzroy Street, London W1T 4BQ, UK

e-mail: tasos.stavrou@arup.com

A. Stavrou - W. Murphy

School of Earth and Environment, University of Leeds, Leeds LS2 9JT, UK

N. Vlachopoulos

Department of Civil Engineering, Royal Military College

of Canada, Kingston K7K 7B4, Canada function of a newly proposed "Defect Intensity $\times$ Persistence" factor. This allow us to standardise the data along specific strength reduction envelopes and to propose generic relationships that cover a wide range of defect geometrical combinations, defect strengths and sample sizes. Accordingly, an attempt is undertaken to refine two existing empirical approaches that consider the effect of scale and micro-defects explicitly for predicting the UCS of rock blocks.

Keywords Rock block strength - Scale effect - Preexisting defects - Synthetic rock block - UDEC . FracMan

\section{Introduction}

Understanding the strength and deformability of rock blocks and their contribution to the overall rock mass behaviour is key for the rock engineering design of underground and surface excavations in civil and mining engineering projects (Stavrou and Murphy 2018). Rock blocks are volumes of macroscopically unjointed intact rock material that are delineated by persistent or non-persistent discontinuities. Their various shapes and sizes are determined by the spatial geometrical arrangement of the fracture network (i.e. intensity, persistence, spacing, termination, sequence of fracturing), which in turn depends on the rock type, the evolution of the stress regime, and the conditions 
under which these discontinuities were developed (Palmstrom 2005).

Depending on the geological history, chemical processes and conditions (i.e. temperatures, pressures, stresses, tectonism) to which the rock material has been subjected, some rock blocks may have developed heterogeneities and/or preferential anisotropy while some other may be relatively homogeneous and isotropic. Heterogeneity is typically expressed by the presence of micro and meso-scale structural features (hereafter referred as "defects") and/or elevated degrees of weathering. On the other hand, defects in homogeneous rocks are very sparse or even absent.

Rock block defects govern the physical, mechanical, dynamic, thermal and hydraulic properties of rock blocks and thus influence the overall behaviour of the rock mass. Depending on their geometrical (i.e. persistence, orientation and frequency) and mechanical characteristics (i.e. open, cement filled), such defects could significantly accelerate the rock failure processes and reduce the strength of the rock blocks (Laubscher and Jakubec 2001). However, due to the practical challenges in evaluating the impact of these defects on the rock block and rock mass strength, the role of micro and meso-scale defects (e.g. grain boundaries, cavities, fissures, veins and open or healed micro-cracks, etc.) is not typically considered in design, with the principal focus mainly being on the assessment of large scale structures (e.g. joints, bedding, faults, etc.).

It is widely recognised that the Unconfined Compressive Strength (UCS) of intact rock decreases with increasing scale due to an increased inherent heterogeneity as a function of volume and the greater probability of randomly and/or critically orientated defects to create failure paths within larger rock volumes (Tsur-Lavie and Denekamp 1982; Hoek and Brown 1997). In confined conditions, it is again recognised that some form of strength reduction with specimen size exists. Previous work by Stavrou and Murphy (2018) examined the combined effect of size and heterogeneity on the confined strength of rock blocks. According to this work, provided that the UCS reduction due to scaling effects is known, the confined strength of rock blocks could be determined by using the linear and non-linear scaling relationships proposed by the authors. This is particularly important in discontinuum numerical modelling where rock blocks are simulated explicitly and represent an essential element of the analysis. Hence, it appears that knowledge of the scale/condition related UCS reduction of rock blocks is key to characterise accurately the behaviour of the rock mass and the rock -support interactions during excavation.

In this study, a series of simulated laboratory tests are performed on samples of varying sizes and defect intensities to examine the combined influence of sample scale and pre-existing defects on the UCS of rock blocks. As part of the modelling process, Discrete Fracture Networks (DFNs) have been embedded into Grain-Based Models (GBMs) within the Universal Distinct Element Code (UDEC) (Itasca 2014) to capture both the fracturing of the intact material and the effect of pre-existing defects. Following the initial calibration of a lab-scale intact (non-defected) rock sample, randomly distributed defects of increased frequency, persistence and strength are integrated in a series of progressively larger in size samples to generate synthetic rock specimens. The results from these experiments are compared with previous studies and the predicted UCS values are analysed in terms of sample size, defect density, persistence and strength.

\section{Effect of Scale and Defects on UCS}

The inverse relationship between the UCS and specimen size has been validated through laboratory and in situ test campaigns for a wide range of lithologies and rock conditions (Mogi 1962; Bieniawski 1968; Pratt et al. 1972; Hoek and Brown 1980) although some exceptions have also been reported in the literature (Pells 2004). The scale beyond which strength becomes independent of the specimen size and/or the density of defects is known as the Representative Elementary Volume (REV) and is considered to be the minimum volume of rock needed to evaluate scale effects and to achieve repeatability of tests results (da Cunha 1990).

To capture the variability of the in situ rock block conditions (e.g. lithology, intensity of micro-defects and degree of weathering) for a wide range of rock block volumes, Yoshinaka et al. (2008) adopted Weibull's statistical theory (Weibull 1939, 1951) and proposed a power law relationship that predicts the reduction of UCS with specimen size as follows,

$\frac{\sigma_{c}}{\sigma_{c .0}}=\left(\frac{d_{e}}{d_{e 0}}\right)^{-k}$ 
where $\sigma_{c}$ and $\sigma_{c .0}$ are the UCS of large and lab-scale specimens respectively, $d_{e}$ and $d_{e 0}$ are their equivalent lengths expressed as a function of their volume (i.e. $d_{e}=V^{1 / 3}$ and $d_{e 0}=V_{0}^{1 / 3}$ ) and the exponent $k=3 / m$ where $m$ is a material constant called the coefficient of uniformity.

The exponent $k$ varies substantially with rock type, strength and material micro-structural heterogeneity and lies between 0.1 and 0.3 for homogeneous strong rocks with UCS between 25 and $250 \mathrm{MPa}$; between 0.3 and 0.9 for highly weathered and/or severely defected rocks and between 0.0 and 0.5 for weak rocks with a UCS between 0.5 and $25 \mathrm{MPa}$ (Fig. 1). Ideally, to define the exponent $k$, a series of large UCS tests are required to capture the variability of strength with size. Apart from the case studies summarised by Yoshinaka et al. (2008) to fit the exponent $k$, other examples include the works by Pierce et al. (2009), Smith and Habte (2011) and Vallejos et al. (2016).
Although several empirical, statistical and theoretical models have been proposed to describe the scale effects on strength (inter alia Weibull 1951; Einstein et al. 1970; Hoek and Brown 1980; Carpinteri 1994), relatively little research has been carried out to develop a practical tool from which practitioners would be able to predict the size/quality-dependent Rock Block Strength (RBS) based on qualitative descriptions or quantitative measurements. The only noticeable exception that explicitly account for rock block defects was proposed by Laubscher and Jakubec (2001) via the Mining Rock Mass Rating (MRMR) classification system which essentially introduced the rock block strength concept (Fig. 2).

The MRMR system expresses the RBS of homogenous rock blocks as a function of a size-corrected Intact Rock Strength (IRS) that is $80 \%$ of a corrected UCS obtained from laboratory scale samples (Fig. 2). This RBS reduction was adopted from earlier work conducted by Hoek and Brown (1980) who

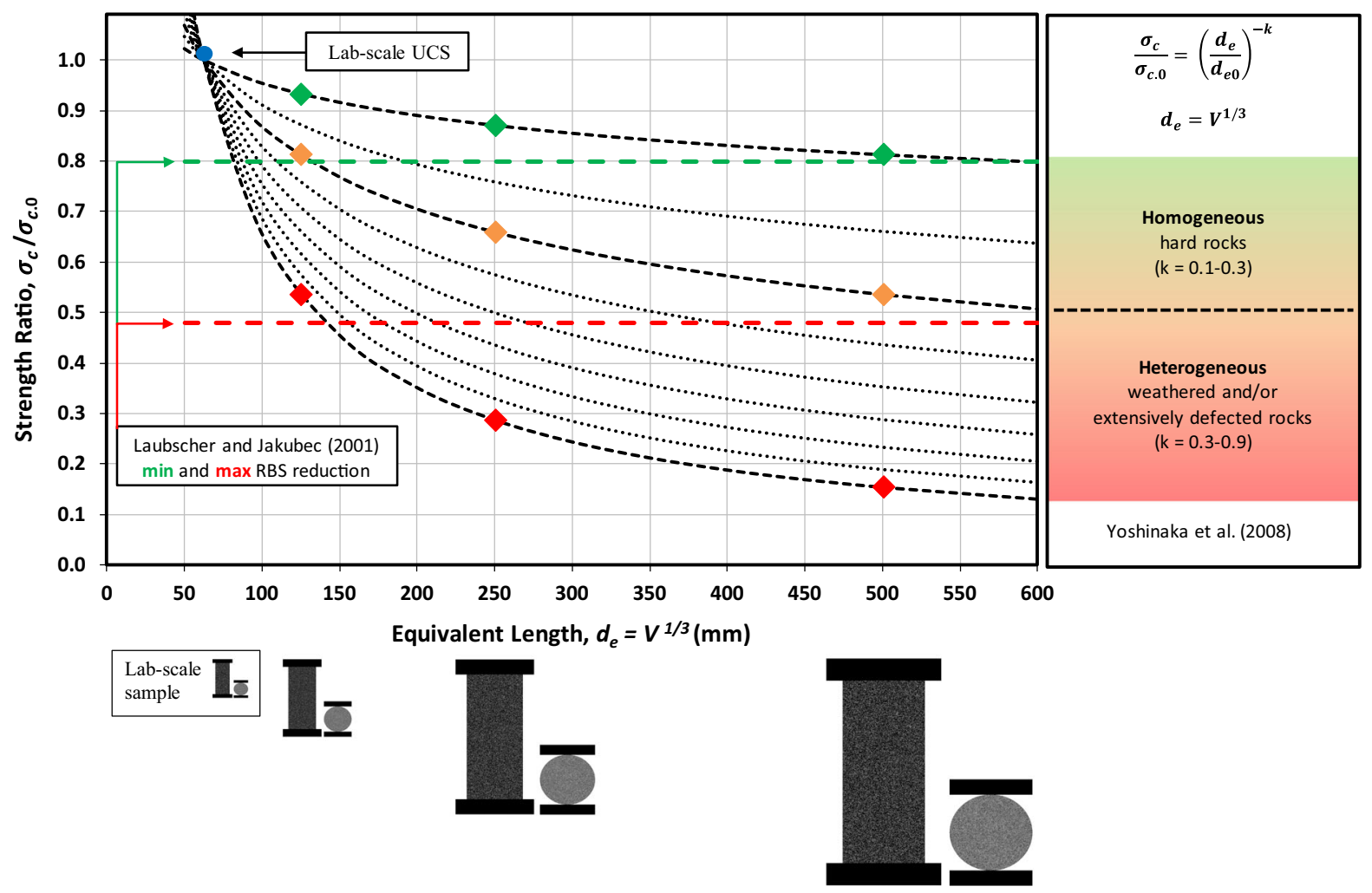

Fig. 1 Scale effect relations for intact rock UCS proposed by Yoshinaka et al. (2008). Also included for comparison are the maximum and minimum Rock Block Strength (RBS) reductions from the relation of Laubscher and Jakubec (2001). Target reduced UCS values for three progressively larger in size numerical samples are shown as green, orange and red symbols respectively. The sample height to width ratio is 2.5 (modified after Pierce et al. 2009) 


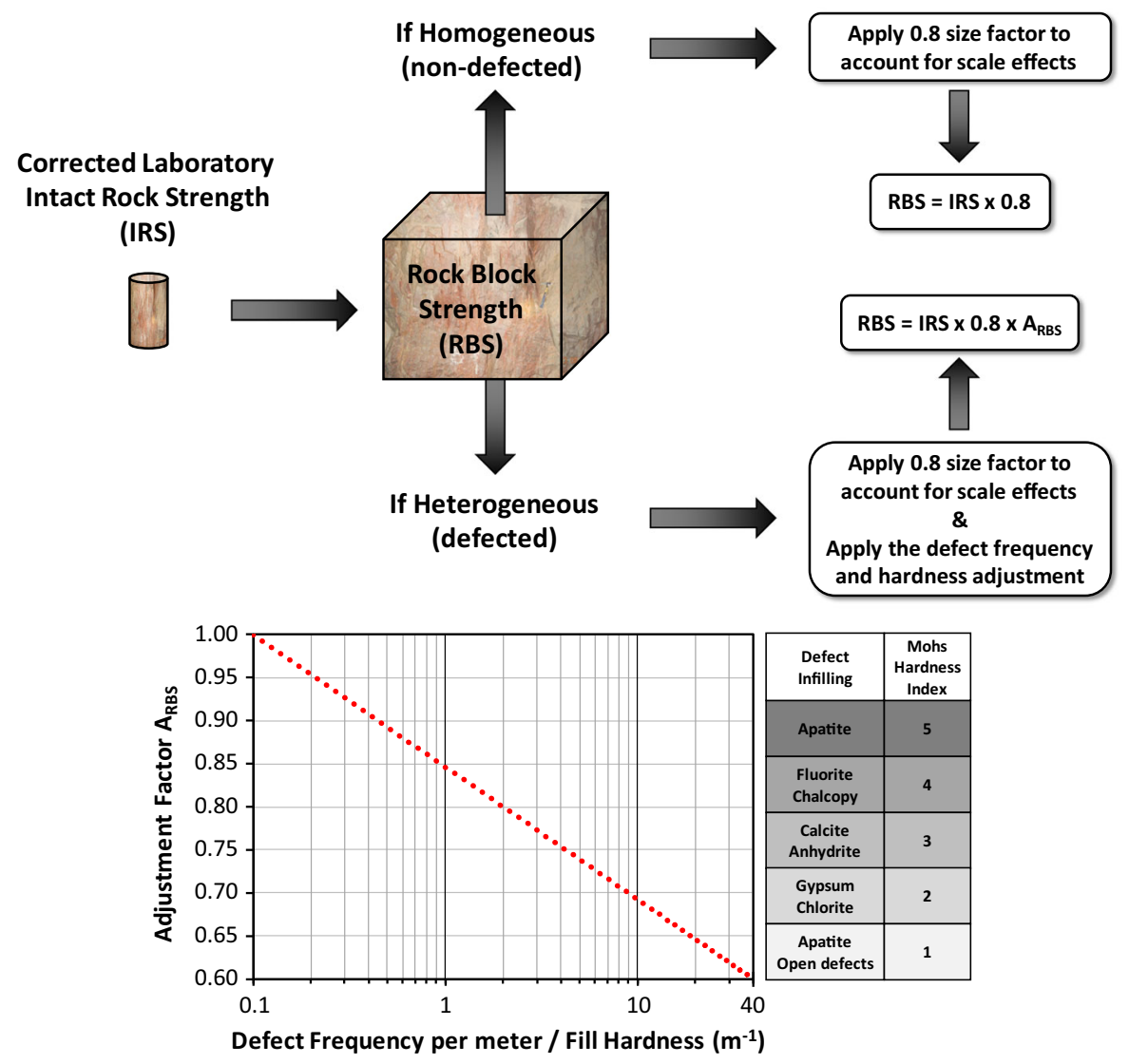

Fig. 2 Rock block strength concept used in the MRMR classification system (Laubscher and Jakubec 2001) and strength adjustment factor (modified after Read and Stacey (2009)

demonstrated that the UCS reduction due to scale effects in homogenous hard rocks is limited by an asymptotic constant value of approximately 0.8 . For heterogeneous rock blocks, the MRMR system reduces the RBS up to $60 \%$ by applying a second adjustment that considers the frequency of defects and their frictional properties (i.e. infill hardness) (Fig. 2). The maximum combined RBS reduction considering both the $80 \%$ size-effect factor and the $60 \%$ defect frequency/hardness adjustment is therefore $48 \%$ of the laboratory derived UCS.

Both the relations of Yoshinaka et al. (2008) and Laubscher and Jakubec (2001) are plotted in Fig. 1 for comparison. As can be observed, the RBS reductions derived from the Laubscher and Jakubec (2001) approach lie approximately between the asymptotes for $k=0.1$ and 0.3 of the Yoshinaka et al. (2008) scaling relationship. For weathered and/or extensively defected rocks, Yoshinaka et al. (2008) proposed RBS reductions that can drop the lab UCS up to $80 \%$ and as such their relation offers more aggressive strength reductions than the approach proposed by Laubscher and Jakubec (2001). Although the comparison suggests that the Laubscher and Jakubec (2001) relation is likely to overpredict the strength of heavily defected rock blocks, Yoshinaka et al. (2008) do not provide any guidelines for selecting the exponent $k$ in their expression. For that reason the Laubscher and Jakubec (2001) methodology remains the only attractive way to estimate the rock block strength based on field measurements (i.e. micro-fracture frequency and mineral infill strength).

An alternative approach to quantify the effect of scale and defects on UCS was proposed by Pierce et al. (2009) who demonstrated how Synthetic Rock Mass (SRM) modelling techniques could be used to supplement existing empirical relationships, such as those described by Laubscher and Jakubec (2001) and 
Yoshinaka et al. (2008). Their work employed a SRM scaling study to assess the impact of defect strength on RBS and related the exponent $k$ of the Yoshinaka et al. (2008) relation to the strength of persistent veins. Their results were very promising and essentially, Pierce et al. (2009) opened the Pandora's box for further SRM studies so that the influence of defect strength, frequency and persistence could be quantified to assess RBS over a wide range of scales and conditions. Following Pierce et al. (2009) recommendations, in this study various $\mu \mathrm{DFN}$ geometries have been embedded into different GBM sizes, to better understand the strength reduction of rock blocks as a function of scale, defect geometry (i.e. intensity, persistence) and defect strength. Based on our numerical findings, guidelines for estimating the strength of defected rock blocks are proposed in an attempt to refine the existing empirical relationships.

\section{Simulation of Synthetic Rock Block Samples (SRB)}

A hybrid modelling approach was employed to create Synthetic Rock Block (SRB) samples to investigate the combined effect of size and pre-existing microdefects on the strength and deformability properties of rock blocks. A SRB model is created by coupling previously generated $\mu \mathrm{DFN}$ geometries within the GBM structure (Fig. 3) and as such it allows the simulation of pre-existing defects within the intact rock matrix. The major advantage of a SRB model is the capability of modelling the fundamental fracturing processes of intact rock (i.e. crack initiation, propagation and coalescence) without resorting complicate constitutive behaviour. The logic is identical with the Synthetic Rock Mass (SRM) modelling approach (Mas Ivars et al. 2007; Pierce et al. 2007) with the only difference being the scale of interest.

Previous numerical investigations on simulated unconfined compression tests have demonstrated the importance of scale and pre-existing defects on the strength, and the resulting failure modes.

Pierce et al. (2009) used the SRM modelling technique within the Particle Flow Code (PFC) to examine the effect of scale on the RBS of extensively defected quartzite from the Bingham Canyon Mine. With progressively increasing sample sizes and decreasing relative vein strengths, it was observed

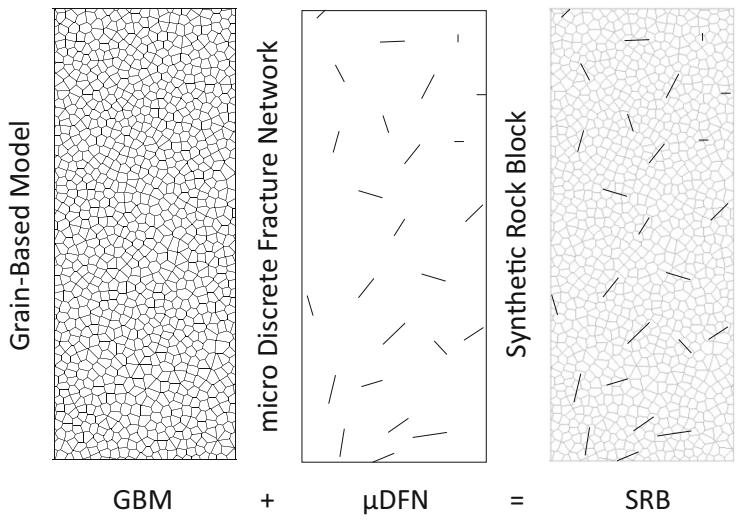

Fig. 3 The different components of a Synthetic Rock Block (SRB) model in UDEC: intact Grain-Based Model (GBM) and micro Discrete Fracture Network $(\mu \mathrm{DFN})$

that RBS falls up to $40 \%$ of the mean laboratory UCS following a power-law trend similar in form to the relation proposed by Yoshinaka et al. (2008).

Zhang et al. (2011) undertook a numerical study in PFC3D to investigate the dependence of specimen size on the UCS of the Yamaguchi marble. In this PFC modelling, it was shown that to capture realistic scale effects on the UCS, the size and number of random pre-existing micro-fractures needs to increase faster than the specimen size considering an exponential expression derived using the fractal theory.

Jakubec et al. (2012) used the SRM approach within PFC to better understand the influence of defects on rock mass strength at the Chuquicamata Mine in Chile. A series of simulated micro-defected samples were tested in unconfined compression and it was revealed that UCS reduces asymptotically as the defect shear strength decreases and the sample size increases. From the acquired results it was concluded that RBS lies approximately between 40 and $45 \%$ of the laboratory UCS values and corresponds well with the RBS estimates given by the Laubscher and Jakubec approach (Laubscher and Jakubec 2001).

Bahrani and Kaiser (2016) coupled GBMs with DFNs using PFC to investigate the influence of specimen size on the strength of non-defected and defected rocks. The UCS of the defected samples showed that it may decrease or increase with increasing specimen size depending on the orientation of defects.

Although some other numerical studies did not include the scale effect in terms of specimen size, the 
influence of size was considered indirectly by simulating pre-existing defects of different intensities within single laboratory or rock block scale samples.

Damjanac et al. (2007) tested in UDEC and PFC large-size GBMs of the Lithophysal Tuff to supplement existing laboratory data and to investigate the variability of mechanical properties as a function of lithophysal porosity. Material heterogeneity was represented explicitly within the models in the form of lithophysal cavities and a strength-deformability decreasing effect was captured with increased porosity due to an increasing tendency for axial splitting.

Lu (2014) developed GBMs in UDEC to investigate the effect of scale and defect intensity distribution on the UCS of flawed rocks. The obtained results demonstrated that for a constant micro-crack density and different flaw lengths the UCS decreases with increasing specimen size up to constant value. Furthermore, GBMs of randomly distributed defects showed a strong correlation between UCS and defect intensity with the reduction of strength also depending on the defect persistence relative to the sample size.

Hamdi et al. (2015) examined the effect of stressinduced micro-cracks on the strength of the Lac du Bonnet granite by using the combined finite-discrete element method (FDEM) within the ELFEN software package. Standard laboratory size samples of varying micro-crack intensities were tested under unconfined and confined compression, and indirect tension (Brazilian test). Their numerical results revealed the strength degradation due to the increase in microcrack intensity, with its impact becoming less severe as confining stresses increase.

Gao and Kang (2016) used the UDEC Trigon approach to investigate under confined and unconfined conditions the impact of pre-existing discontinuities on large scale coal samples. A significant reduction in the peak strength was observed as DFN intensity was increased. Their results also demonstrated that DFN intensity has little impact on the residual strength and that with increasing confinement, both the peak and residual strengths tend to increase but with the latter at a significantly higher increasing rate.

From all the aforementioned numerical studies, it has been generally shown that UCS decreases as sample size and/or defect intensity increase, with other factors such as defect orientation, persistence and strength being equally important.

\subsection{UDEC Grain-Based Models (GBM)}

\subsubsection{GBM Mechanical Behaviour}

In a UDEC GBM, a rock specimen is treated as a packing of randomly-sized deformable grains which are bonded together along their boundaries (Fig. 4). The mechanical behaviour of a GBM is controlled by the grain-to-grain interface micro-properties and the geometrical arrangement of the Voronoi blocks (i.e. size and size distribution). The micro-mechanical properties refer to the deformability properties of the grains together with the strength and stiffness parameters of the contact interfaces that separate them. Once the contact strength is exceeded either in shear or in tension, the bond between the grains breaks and a compression-induced, tensile or sliding crack is initiated (Fig. 4). During this process, the cohesive and tensile strengths are reduced to zero (instantaneous softening) and the friction angle decreases to a residual value. As a technique, the micro-mechanical modelling represents a valuable numerical tool to build the micro-structure of rocks and hence to study the mechanisms of crack generation, progressive fracture propagation and intact rock disaggregation (Gao et al. 2014).

\subsubsection{Small-Scale GBM Intact Rock Calibration}

A rectangular $50 \times 125 \mathrm{~mm}$ sample and a circular $50 \mathrm{~mm}$ in diameter sample were initially generated to simulate laboratory scale compression (unconfined and confined) and indirect tension (Brazilian) experiments. The average edge length of the Voronoi blocks was specified equal to $5 \mathrm{~mm}$ and a relatively nonuniform grain size distribution was built to mimic the internal micro-structural heterogeneity of real rocks. Visual inspection of the samples suggests that the ratio largest grain size—-specimen diameter is at least 10:1. This grain size was chosen to ensure the numerical efficiency of the larger numerical samples that would be used later in the scaling analysis. For all the simulated compression tests, a constant velocity of $0.005 \mathrm{~m} / \mathrm{s}$ (i.e. loading rate) was applied in the $y$-direction at both the upper and lower platens of the sample, and a servo-control function was used to control the progressive response of the samples during failure. Figure 5 illustrates the boundary conditions 

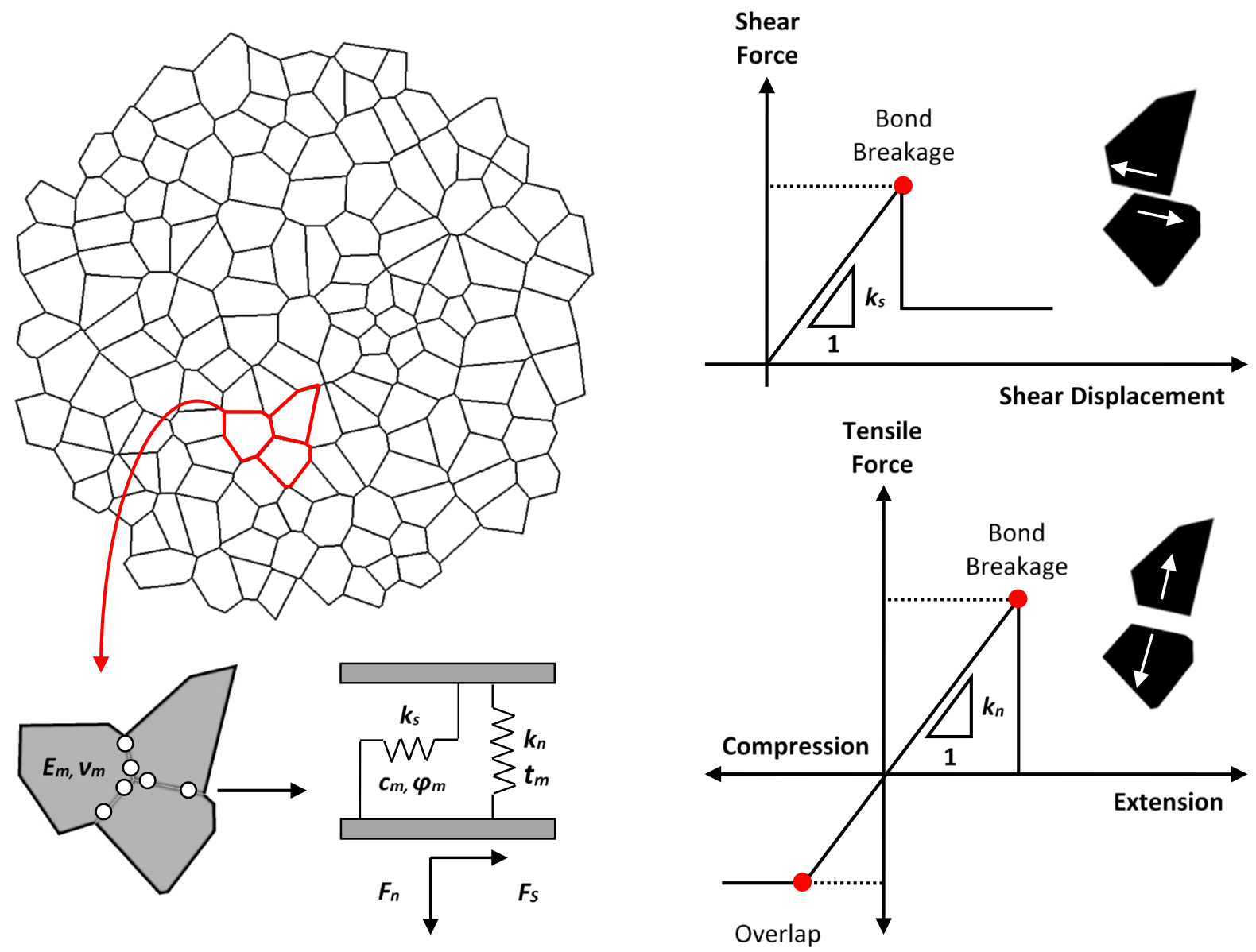

Fig. 4 Structure, micro-mechanical properties and constitutive behaviour of UDEC GBM model (Stavrou and Murphy 2018)

and the stress/strain monitoring locations (i.e. history points) used at the unconfined compression tests.

A set of typical lab-scale macro-mechanical parameters were defined to be used as target values for the calibration of the lab-scale GBMs. The calibration process followed the procedures outlined by Kazerani and Zhao (2010) and Gao and Stead (2014). For this study a baseline UCS of $50 \mathrm{MPa}$ was selected to describe the lab-scale intact rock strength. Table 1 lists the target intact rock macro-mechanical and the calibrated micro-mechanical properties respectively, while Fig. 6 illustrates the calibrated stress-strain response for the unconfined compression test and the associated sample damage. Initially the specimen behaves elastically and then, after the peak load has been reached, the specimen experiences a rapid loss of strength and fails due to axial splitting and accumulation/interaction of micro-tensile fracturing.

\subsubsection{Large-Scale GBM Intact Rock Calibration}

To investigate the effect of size, three progressively larger in size samples with diameters of 100, 200 and $400 \mathrm{~mm}$ and a height-to-width ratio of 2.5 were generated in UDEC. All models have a similar mean grain size (i.e. $5 \mathrm{~mm}$ ) and size distribution as the lab scale specimens. Initially, the previously calibrated intact rock micro-mechanical properties were adopted and a strength degradation approach was followed to re-calibrate the samples and to capture the expected size-dependant RBS reduction for homogenous and non-defected rocks suggested by Laubscher and Jakubec (2001) and Yoshinaka et al. (2008). The micro-strength properties of the $400 \times 1000 \mathrm{~mm}$ sample were adjusted considering the Laubscher and Jakubec $80 \%$ size factor to derive a target UCS value equal to $40 \mathrm{MPa}$ (i.e. $80 \%$ of the baseline UCS of $50 \mathrm{MPa}$ ). Since this strength reduction coincides well 


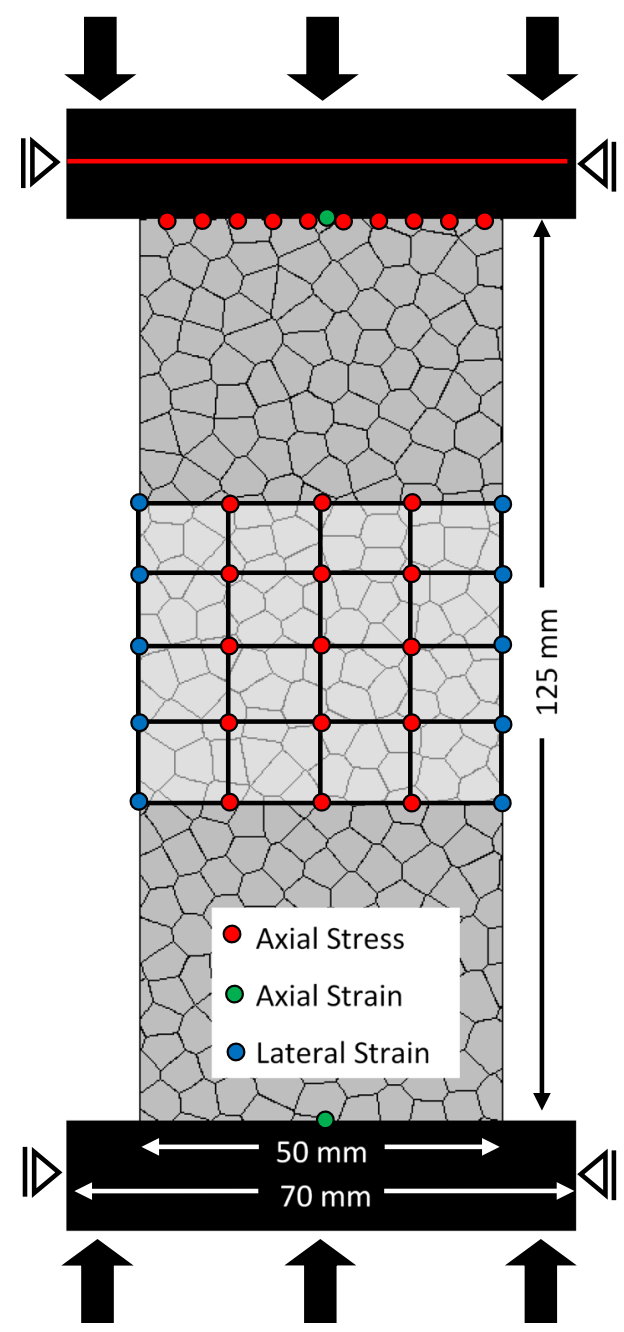

Fig. 5 Layout, boundary conditions and monitoring locations (i.e. UDEC history points) of the unconfined compression tests

with the least strength decrease proposed by the Yoshinaka et al. (2008) relation for large samples, the $200 \times 500 \mathrm{~mm}$ and $100 \times 250 \mathrm{~mm}$ samples were calibrated to follow the asymptote for an exponent $k=0.1$. Table 2 presents the calibrated micro-mechanical properties for the non-defected large samples.

Figure 7 shows the target reduced UCS values together with the generated stress-strain responses and associated failure modes. Regardless of the size it is observed that all specimens fail under similar failure patterns, which is the initiation, propagation and coalescence of axial micro-tension cracks parallel to the loading direction followed by macroscopic fracture zones.
Table 1 Target lab-scale macro-mechanical and calibrated micro-mechanical properties

\begin{tabular}{|c|c|c|c|}
\hline \multicolumn{2}{|l|}{ Properties } & Units & Values \\
\hline \multicolumn{4}{|c|}{ Target macro-mechanical properties } \\
\hline UCS & $\sigma_{i}$ & $\mathrm{MPa}$ & 50 \\
\hline Modulus ratio & $M R$ & - & 400 \\
\hline Young's modulus & $E_{i}$ & GPa & 20 \\
\hline Poisson's ratio & $v_{i}$ & - & 0.25 \\
\hline \multirow[t]{3}{*}{ HB constants } & $m_{i}$ & - & 15 \\
\hline & $s$ & - & 1 \\
\hline & $a$ & - & 0.5 \\
\hline Secant slope & $N_{\varphi}$ & - & 6.8 \\
\hline Cohesion & $c$ & $\mathrm{MPa}$ & 9.6 \\
\hline Friction angle & $\varphi$ & {$\left[{ }^{\circ}\right]$} & 48.1 \\
\hline Tensile strength & $\sigma_{t}$ & $\mathrm{MPa}$ & 3.3 \\
\hline \multicolumn{4}{|c|}{ Calibrated SRB micro-mechanical properties } \\
\hline Grain Young's modulus & $E_{m}$ & $\mathrm{GPa}$ & 26.0 \\
\hline Grain Poisson's ratio & $v_{m}$ & - & 0.25 \\
\hline Contact normal stiffness & $k_{n}$ & $\mathrm{GPa} / \mathrm{m}$ & 15,600 \\
\hline Contact shear stiffness & $k_{s}$ & $\mathrm{GPa} / \mathrm{m}$ & 14,040 \\
\hline Contact stiffness ratio & $k_{s} / k_{n}$ & - & 0.9 \\
\hline Contact cohesion & $c_{m}$ & $\mathrm{MPa}$ & 11.5 \\
\hline Contact friction angle & $\varphi_{m}$ & {$\left[{ }^{\circ}\right]$} & 48.1 \\
\hline Contact tensile strength & $t_{m}$ & $\mathrm{MPa}$ & 3.3 \\
\hline Residual cohesion & $c_{m r}$ & $\mathrm{MPa}$ & 0.0 \\
\hline Residual friction angle & $\varphi_{m r}$ & {$\left[{ }^{\circ}\right]$} & 25 \\
\hline Residual tensile strength & $t_{m r}$ & $\mathrm{MPa}$ & 0.0 \\
\hline
\end{tabular}

\subsection{Micro Discrete Fracture Networks ( $\mu \mathrm{DFN})$}

Once the UCS of the homogenous samples was calibrated, a series of unconfined compression tests were run by integrating the $\mu \mathrm{DFN}$ geometries. DFN modelling has become a powerful tool over the years to realistically capture the influence of discontinuity geometry within fractured rocks for a wide variety of projects. Treated as discrete features, fractures and the overall joint geometry are simulated by using random variables of the joint geometrical features such as location, size and orientation. These random variables are usually assigned a probability distribution in order to determine their numerical value and generate the geometry (Xu and Dowd 2010). The stochastic modelling of fracture network geometries and its implementation into geological and rock engineering 

unconfined compression test showing the calibrated stress-strain response and sample damage
Fig. 6 Simulated

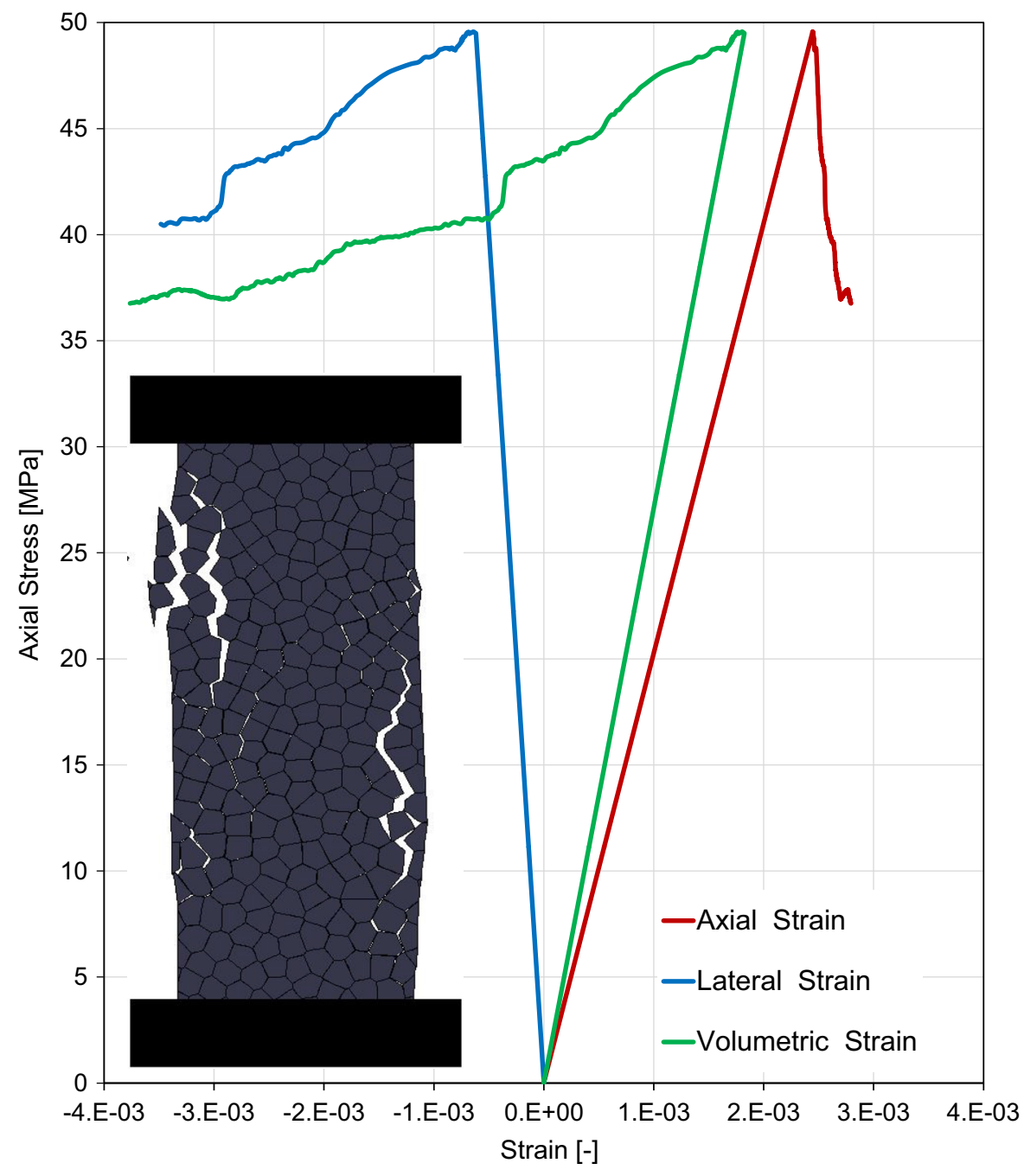

Table 2 Calibrated micromechanical properties for the large-scale non-defected samples

\begin{tabular}{lllllc}
\hline Property & Units & \multicolumn{4}{l}{ Sample size $(\mathrm{mm})$} \\
\cline { 3 - 6 } & & $50 \times 125$ & $100 \times 250$ & $200 \times 500$ & $400 \times 1000$ \\
\hline Target UCS strength & $\mathrm{MPa}$ & 50.0 & 46.4 & 43.1 & 40.0 \\
Contact cohesion & $\mathrm{MPa}$ & 11.5 & 11.3 & 10.7 & 9.4 \\
Contact friction angle & $\left.{ }^{\circ}\right]$ & 48.1 & 47.5 & 46.2 & 42.4 \\
Contact tensile strength & $\mathrm{MPa}$ & 3.3 & 3.3 & 3.3 & 3.3 \\
\hline
\end{tabular}

projects has been studied by various researchers (Baecher 1983; Dershowitz and Einstein 1988; Davy et al. 2013; Farahmand et al. 2018; Vazaios et al. 2017, 2018) mostly focusing on meso- and large-scale discontinuity features and their influence at a rock mass scale. In such cases, DFN models are generated based on discontinuity data collected in the field by either employing conventional mapping techniques (e.g. scanlines, convex or circular mapping windows etc.) or remote sensing approaches (e.g. photogrammetry, laser scanning etc.) by using $3 \mathrm{D}$ geometrical models of the exposed rock mass.

Although meso and large scale DFN geometries have been adopted in various studies to assess the 


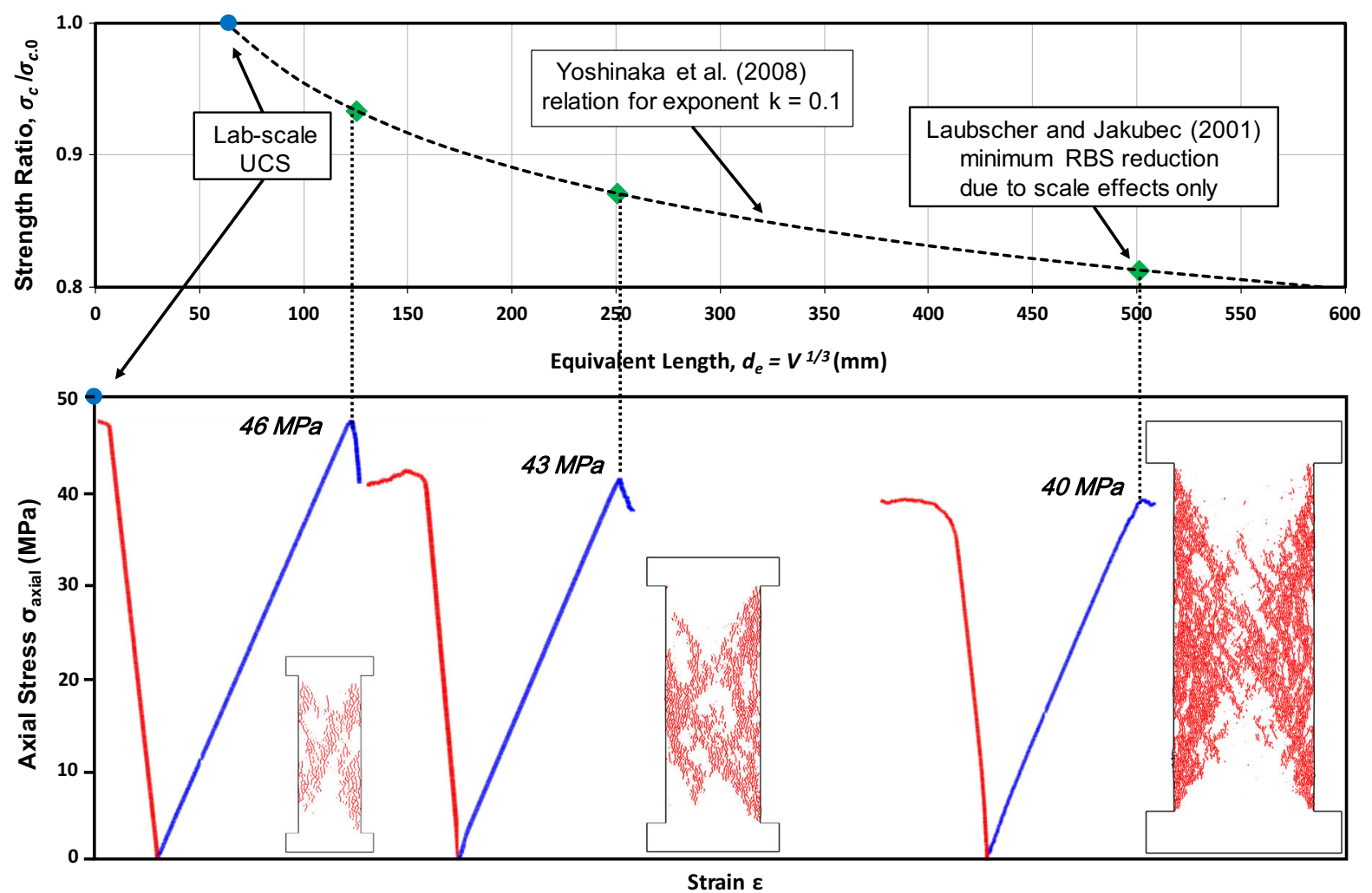

Fig. 7 Calibrated stress-strain curves and sample damage for the non-defected numerical samples (the damaged samples shown are not in scale)

jointed material mechanical properties at a rock mass scale, at a rock block scale those meso and large-scale rock mass structures are not valid to be used. Therefore, there is the requirement to differentiate the stochastic nature of micro/meso-scale defects from larger scale discontinuities (Hamdi et al. 2015).

The micro Discrete Fracture Network geometries (herein called $\mu \mathrm{DFN}$ ) (Hamdi et al. 2015) introduced in this study refer to the rock heterogeneity at very small scales which can include geometrical features like grain boundaries, fissures, veins and microcracks. Micro-cracks present within a macroscopically "intact" rock block can be "healed" and "cemented" with a material weaker or stronger than the host rock, or can be open defects due to the geological history of the medium. This micro-structure can be identified during mapping or core logging if macroscopically visible, or in the laboratory by employing imaging techniques including the image analysis of thin sections (Lim et al. 2012), processing with CAD software (Turichshev and Hadjigeorgiou 2017),
X-Ray CT imaging (Nasseri et al. 2009) etc. (Figure 8). In this way, the micro-crack orientation and intensity (persistence and density) can be evaluated quantitively and serve as input parameters for the generation of the $\mu \mathrm{DFN}$ geometrical models. This approach can assist in considering site specific conditions and tie the numerical results to a specific rock mass, which is however, out of the scope of this study.

Regarding the determination of size and location of the simulated joints, it is common practice to use one of the intensity measures proposed by Dershowitz and Herda (1992) either in one dimension (linear $-P_{10}$ ), two dimensions (areal $-P_{21}$ ) or three dimensions (volumetric $-P_{32}$ ), since these measures allow for the quantification of fracture frequency and size. Based on the dimension of the sampling region and the dimension of the joint feature, these measures have been proven particularly useful in providing quantifiable means of joint geometry assessment, and in this study both the $P_{10}$ (measured as the numbers of fractures per unit length of scan line or borehole core) 

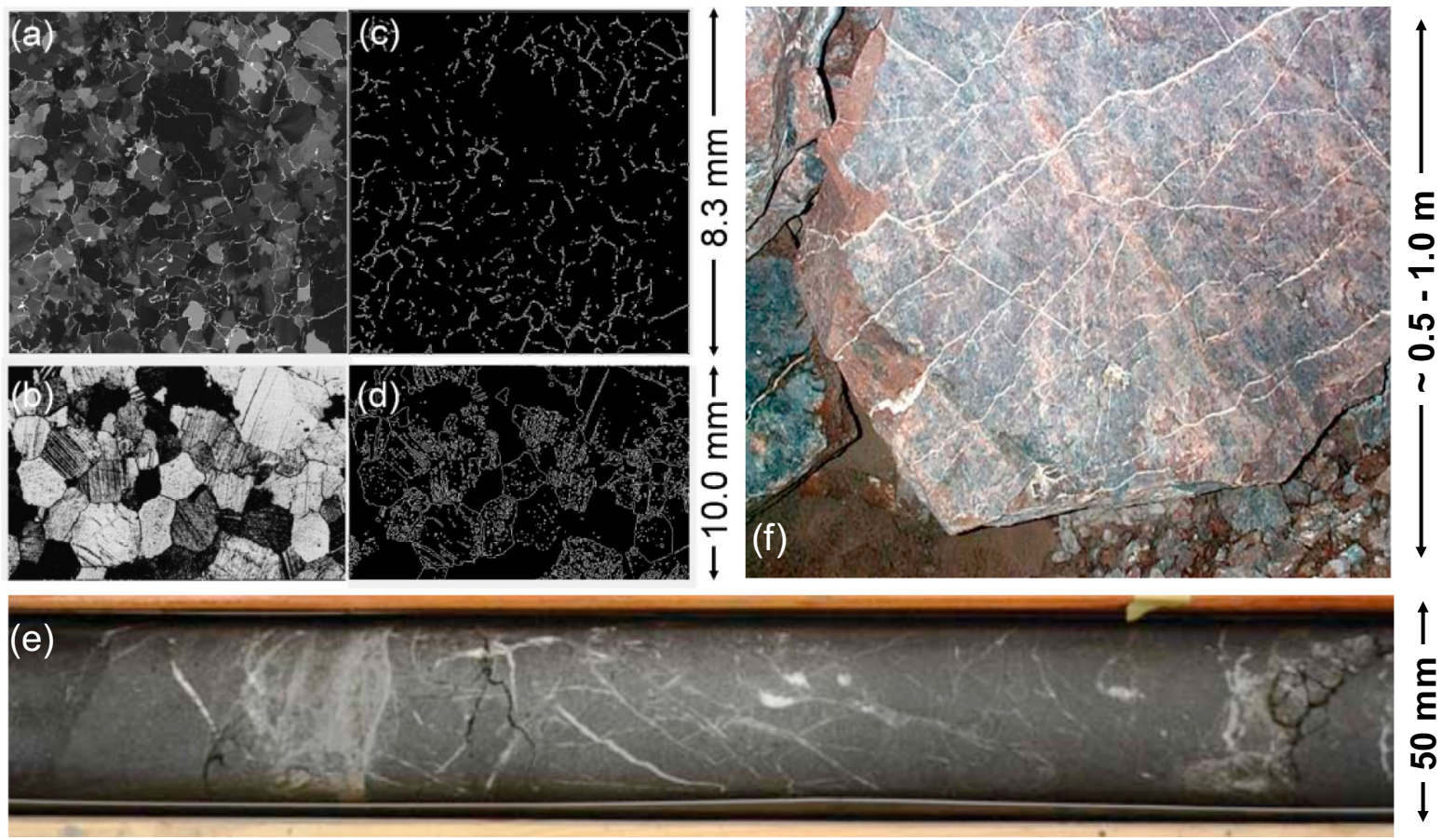

Fig. 8 Defects at different sampling scales: SEM images of micro-crack distributions in thin sections of a Lac du Bonnet granite (Lim et al. 2012), and b Wombeyan marble (Rosengren and Jaeger 1968). Traces of the micro-cracks were obtained from the image processing package provided in MATLAB for

and $P_{21}$ (measured as the ratio of the sum of the fracture trace lengths to the sampling area) are used to determine the crack system geometry within the rock specimens.

More specifically, various target fracture frequency $P_{10}$ values were specified for different crack persistence lengths and specimen sizes. The generation of the $\mu \mathrm{DFN}$ geometries was conducted following a fracture frequency (i.e. fracture per meter) logic to allow a direct comparison with the work of Laubscher and Jakubec (2001), which currently is the only practical tool for quantifying the effect of pre-existing fractures on the strength of rock blocks. The defect geometrical models were mainly generated by using the DFN generator Fracman (Dershowitz et al. 2014) (Fig. 9), and the models created by Stavrou and Vazaios (2018) were additionally used to enhance the obtained results.

For the DFN generated, the fracture intensity $P_{10}$ was used as the primary target parameter by applying the Baecher model for non-persistent discontinuities. The assigned $P_{10}$ value was verified by introducing c Lac du Bonnet granite, and d Wombeyan marble (Vazaios et al. 2018); e veins infilled with quartz within sandstone core; f defects cemented by gypsum in the rock block scale (Jakubec 2013)

"virtual" scanlines within the numerical model, as illustrated in Fig. 10. The defects were sampled along those scanlines and the average value of $P_{10}$ was compared to the one used as input to ensure that the model complies with it. Once $P_{10}$ was in agreement with the targeted value, the $\mu \mathrm{DFN}$ geometry was introduced into the large-scale calibrated UDEC GBM models. To minimize the creation of preferential planes of weakness and the potential for anisotropic behaviour, the pre-existing defects were assigned an arbitrary orientation between $0^{\circ}$ and $90^{\circ}$ with a uniform probability distribution.

\section{Analysis of Scale Effects}

\subsection{Matrix of Modelling Scenarios}

To investigate scale effects on the strength of defected samples, the current study considers two cases of numerical simulations: 
Fig. 9 a $3 \mathrm{D} \mu \mathrm{DFN}$

generated in Fracman,

b defects intersecting a specific plane, $\mathbf{c}$ traces generated by the defectplane intersection, and d defect traces imported in the UDEC GBM model
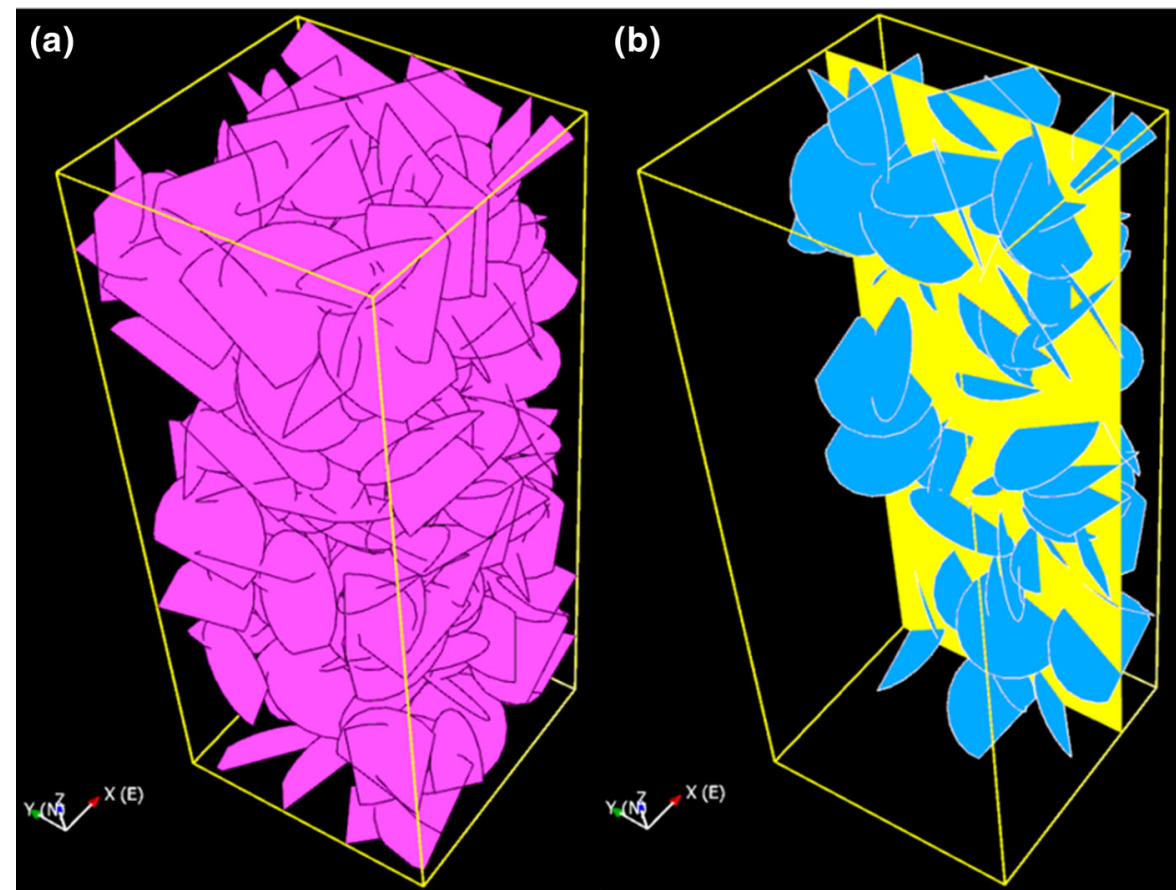

(c)

(d)

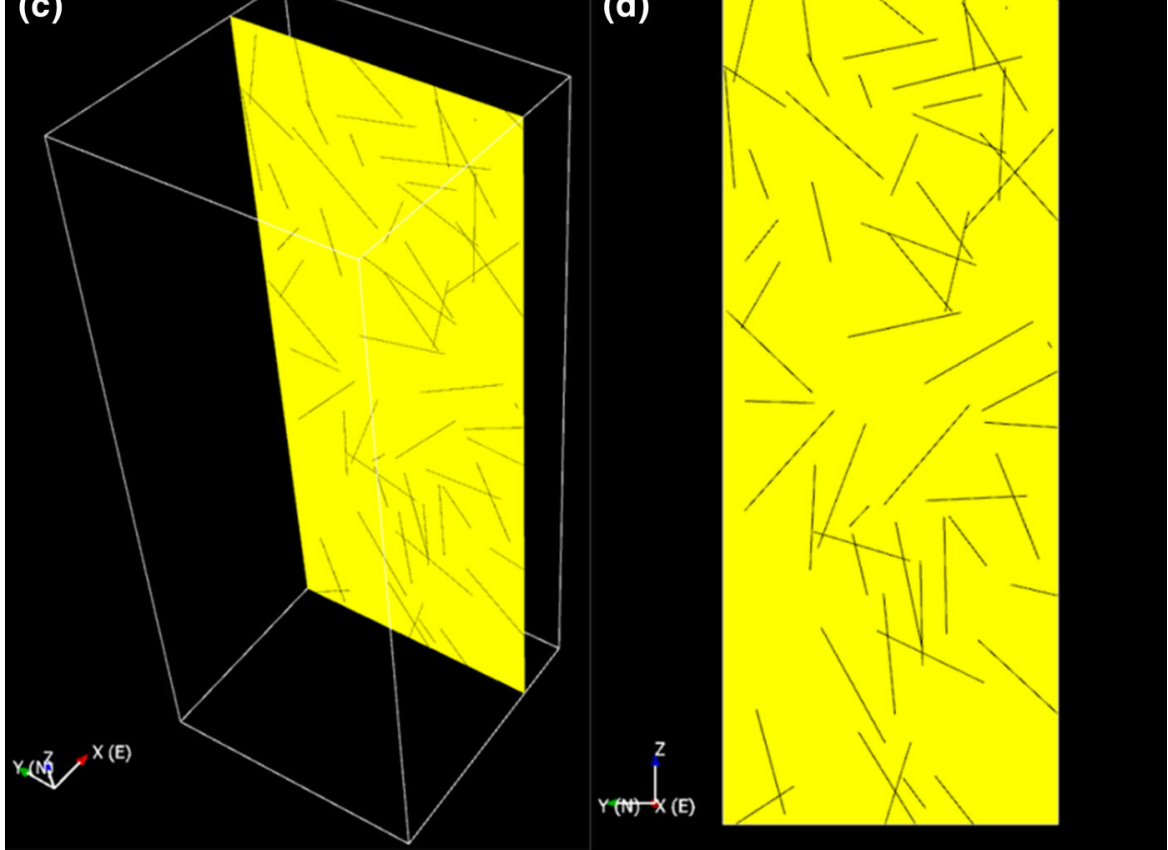

Case 1 Various geometries of randomly distributed "open" defects were embedded into the large-scale calibrated intact GBMs to assess the combined impact of defect intensity, persistence and specimen size. In the adopted approach, the number of defects is proportional to the volume of the specimens. The generated cracks in this case 1 were modelled as "open defects" and assumed to be purely frictional (i.e. zero cohesion and tensile strength), with the friction angle and stiffness values being identical to those of the calibrated intact GBMs (see Table 1). 


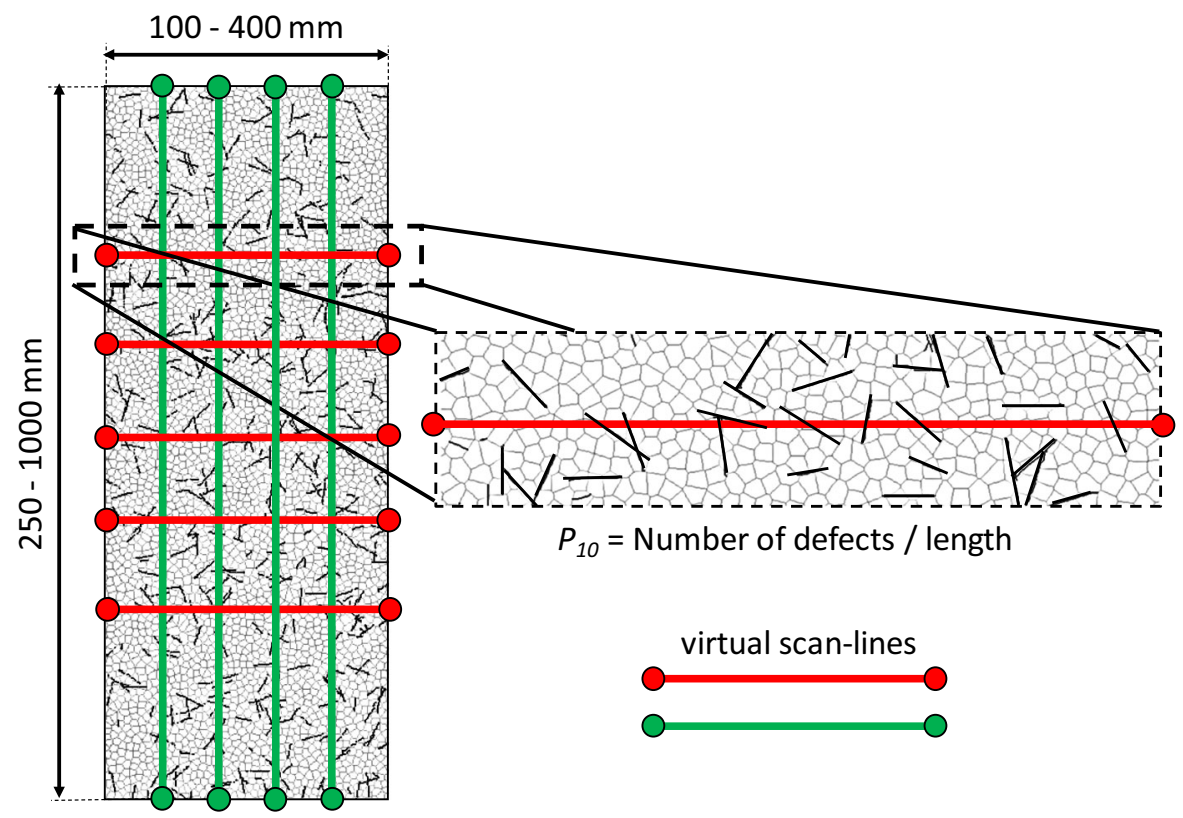

Fig. $10 \mu \mathrm{DFN}$ mapping along virtual scan-lines to confirm the target $P_{10}$ values

Case 2 Further analysis was undertaken by strengthening the defects for some of the previously generated SRB models to assess the combined impact of defect strength, intensity, persistence and specimen size. A parametric analysis was employed where defect strength (i.e. cohesion and tensile strength) was increased by $50 \%$ and $100 \%$ in respect to the baseline intact rock strength and these results where compared with the predicted UCS values for defect strength of $0 \%$ ("open" defects).

For the purposes of this study, $16 \mu \mathrm{DFN}$ groups of increasing fracture intensity and persistence were incorporated within the previously calibrated largescale intact GBMs (Table 3). For each $\mu$ DFN group and sample size, $2-3$ different $\mu \mathrm{DFN}$ realizations were generated by using identical geometric input parameters to examine the repeatability of the results. Table 3 presents the matrix of modelling scenarios and Fig. 11 illustrates examples of the different generated SRB models.

\subsection{Geometrical Assessment}

Prior to the mechanical property evaluation of the various samples, a rigorous geometrical assessment of the generated $\mu$ DFNs was conducted. The first step in this procedure involved the investigation of the relationship between the lineal fracture intensity $P_{10}$,

Table 3 Matrix of modelling scenarios considered to generate SRB models

\begin{tabular}{|c|c|c|c|c|c|c|c|c|c|c|c|}
\hline $\begin{array}{l}\text { Width } \\
(\mathrm{mm})\end{array}$ & $\begin{array}{l}\text { Height } \\
(\mathrm{mm})\end{array}$ & $\begin{array}{l}\text { Area } \\
\left(\mathrm{mm}^{2}\right)\end{array}$ & $\begin{array}{l}\text { Volume } \\
\left(\mathrm{mm}^{3}\right)\end{array}$ & $\begin{array}{l}\mathrm{d}_{\mathrm{e}} \\
(\mathrm{mm})\end{array}$ & $\begin{array}{l}\text { No of blocks (- } \\
\text { ) }\end{array}$ & $\begin{array}{l}P_{10} \text { cases } \\
(\text { defects } / \mathrm{m})\end{array}$ & & Persi & tence & cases (1 & \\
\hline 50 & 125 & $6.25 \mathrm{E}+03$ & $2.5 \mathrm{E}+05$ & 63 & 300 & - & & - & & & \\
\hline 100 & 250 & $2.50 \mathrm{E}+04$ & $2.0 \mathrm{E}+06$ & 125 & 1100 & $10 \quad 20$ & 40 & 0.01 & 0.02 & 0.04 & 0.10 \\
\hline 200 & 500 & $1.00 \mathrm{E}+05$ & $1.6 \mathrm{E}+07$ & 250 & 4100 & & & & & & \\
\hline 400 & 1000 & $4.00 \mathrm{E}+05$ & $1.3 \mathrm{E}+08$ & 501 & 16,200 & & & & & & \\
\hline \multicolumn{6}{|l|}{ Case 1} & $\sqrt{ } \sqrt{ }$ & $\sqrt{ }$ & $\sqrt{ }$ & $\sqrt{ }$ & $\sqrt{ }$ & $\sqrt{ }$ \\
\hline \multicolumn{2}{|l|}{ Case 2} & & & & & $\sqrt{ } \sqrt{ } \sqrt{ }$ & $\sqrt{ }$ & $\sqrt{ }$ & - & $\sqrt{ }$ & - \\
\hline
\end{tabular}




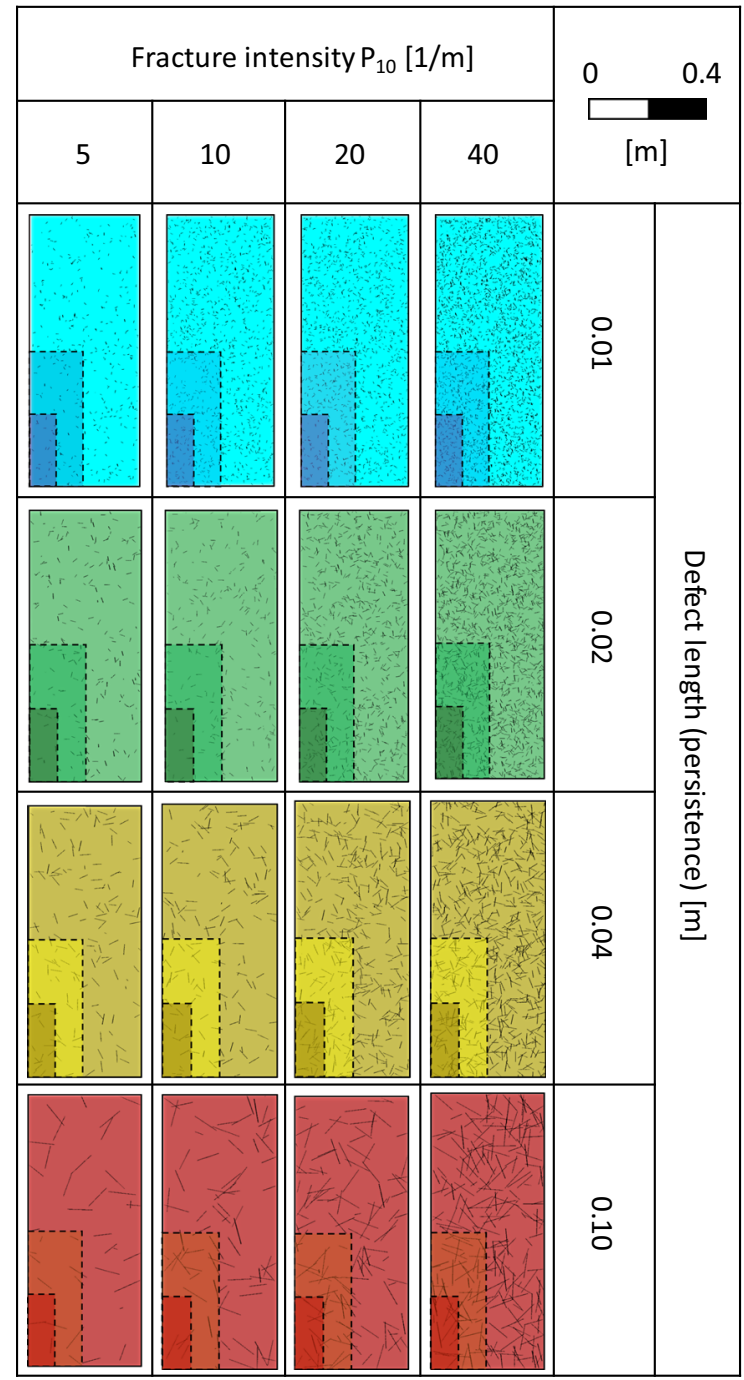

Fig. 11 Matrix of SRB models for $16 \mu \mathrm{DFN}$ groups of increasing defect intensity and persistence and 3 specimen sizes (i.e. $100 \times 250 \mathrm{~mm}, 200 \times 500 \mathrm{~mm}$ and $400 \times 1000 \mathrm{~mm}$ )

serving as an input parameter, and the measured areal fracture intensity $P_{21}$ depending on the utilized defect length $L_{d}$. By plotting $P_{10}$ as a function of the product between $P_{21}$ and the defect persistence $L_{d}$ (Fig. 12a), it can be observed that a linear relationship can be acquired with the slope of the best-fit line varying depending on the defect length. Further analysis of the obtained results reveals that the slope values can be expressed as a power-law function of the defect length (i.e. defect persistence), as observed in Fig. 12b. By coupling those two plots it becomes evident that if the defect persistence is known and either $P_{10}$ or $P_{21}$ is available, the third quantity can be directly backcalculated.

Additionally, the number of defects for each of the investigated DFN geometries was evaluated for each specimen size. From Fig. 12c, it can be observed that for a specific specimen size the number of defects in the model increases in an approximately non-linear fashion as the areal fracture intensity $P_{21}$ increases. Furthermore, the acquired results demonstrate that this increase in the defect number with increasing $P_{21}$ depends on the specimen size (Fig. 12d). More specifically, in the smaller samples the increase in the defect number occurs at a lower rate than in the larger specimens. The relationship between the defect number increase rate and the sample size can be described by an exponential curve (Fig. 12d), and this observation is in agreement with the argument made by Hoek and Brown (1997) that larger rock block volumes are more likely to be influenced by an increased population of defects. Additionally, it becomes evident that this rate is influenced by the defect persistence with smaller defect lengths producing higher rates with increasing sample size. On the contrary, as the defect persistence increases the defect number increase rate decreases.

\subsection{Predicted Rock Block Strength}

\subsubsection{Influence of Defect Persistence and Intensity}

The results from the scaling analysis generally suggest that the UCS of rock blocks is strongly influenced by the presence of "open" pre-existing defects. Figure 13 exhibits the predicted UCS values in respect to the sample equivalent length $\left(d_{e}\right)$ and $\mu \mathrm{DFN}$ intensity $P_{10}$. The predicted UCS values from the SRB experiments have been normalised to the intact lab UCS of $50 \mathrm{MPa}$. As can be seen, substantial reductions in strength are recorded as defect intensity and persistence increase. The results of the samples with persistence equal to $0.1 \mathrm{~m}$ were not included in Fig. 13 as strength dropped rapidly at about 10-20\% of the intact rock UCS and then remained constant. The effect of specimen size is particularly important at low fracture frequencies (due to the greater areal size of solid intact rock bridges in between the micro-defects) and becomes less significant for higher defect intensities and defect trace lengths (continuities). This behaviour indicates that REV has been achieved for the highly defected 
(a)

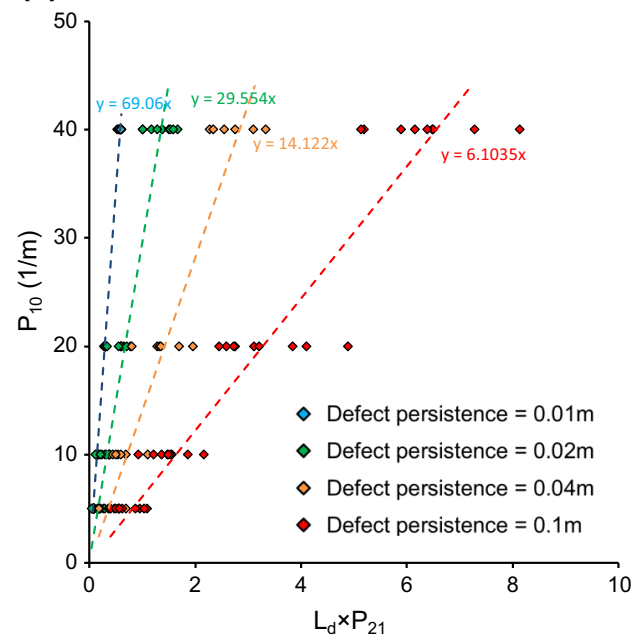

(c)

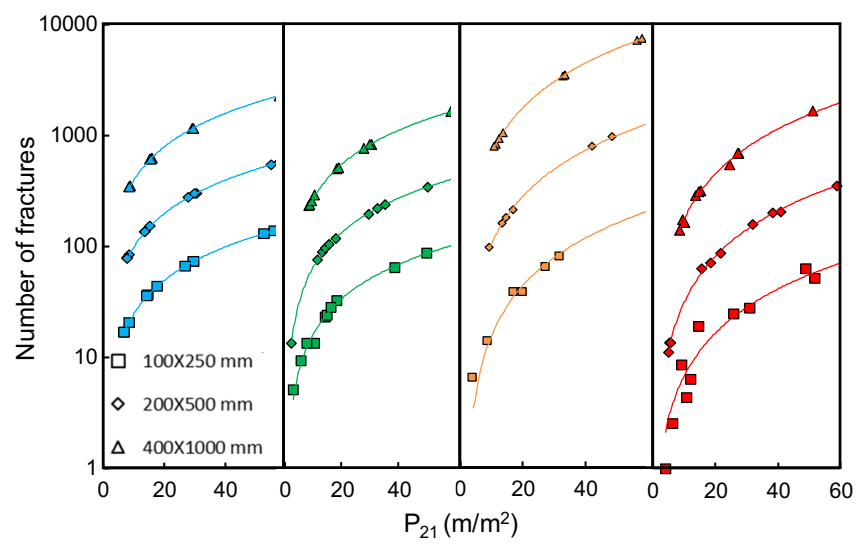

(b)

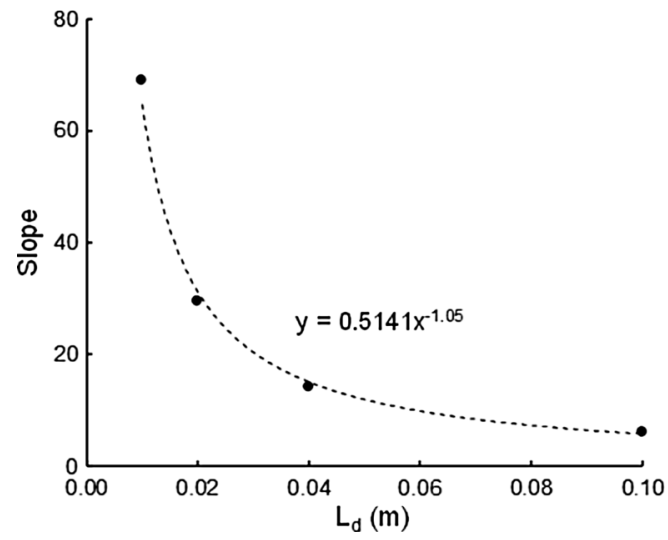

(d)

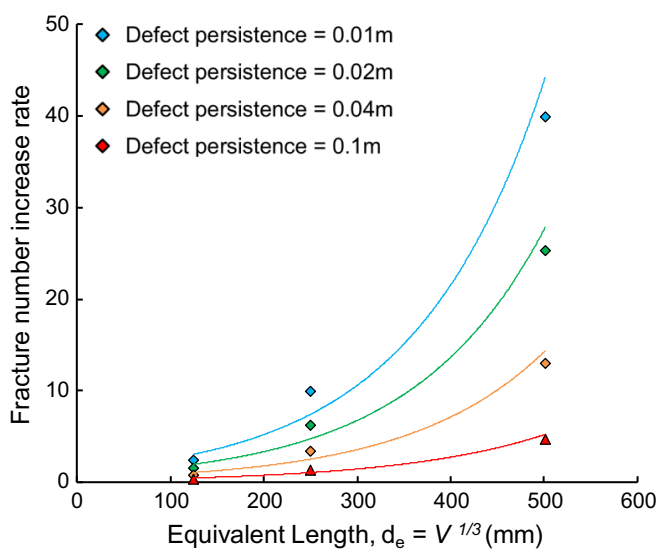

Fig. 12 a The linear fracture intensity $P_{10}$ expressed as a function of the product between areal fracture intensity $P_{21}$ and defect length $L_{d}$. b Slope of the best-fit lines in Fig. 12a as a function of the defect length $L_{d}$. c Linear relationship between $P_{21}$ and number of fractures (vertical axis is in a logarithmic

samples even from the relatively smaller samples (i.e. $100 \times 250 \mathrm{~mm}$ ) while larger samples seem to be required to achieve a constant response for the less broken micro-defected samples. For the specimens with large defect persistence (i.e. $0.04 \mathrm{~m}$ and $0.1 \mathrm{~m}$ ), an increase of strength with scale was also observed due to an increased contribution of the intact rock bridges within the samples and because at smaller scalers the large defects reduce significantly the loading capacity of the specimen.

Figure 13 also shows the Yoshinaka et al. (2008) and Laubscher and Jakubec (2001) strength limits. From these graphs it appears that the maximum RBS scale) for each sample size. Note the significant increase in the slope of the best-fit line for the largest sample. $\mathbf{d}$ Rate of fracture number (slope of best-fit lines in Fig. 12c) increases exponentially with sample size

reduction derived by the Laubscher and Jakubec (2001) relationship (i.e. $48 \%$ of the baseline UCS), corresponds reasonably well with the strengths of the large samples with defect persistence of $0.01 \mathrm{~m}$, possibly suggesting that this method describes successfully the behaviour of rock blocks influenced by micro-heterogeneities in the grain scale. However, the UCS of specimens with persistence $0.02 \mathrm{~m}, 0.04 \mathrm{~m}$ and $0.1 \mathrm{~m}$ respectively is underestimated by Laubscher and Jakubec (2001) but further testing is required to validate this observation. On the other hand, the scale effect asymptotes proposed by Yoshinaka et al. (2008) allow for more dramatic strength 


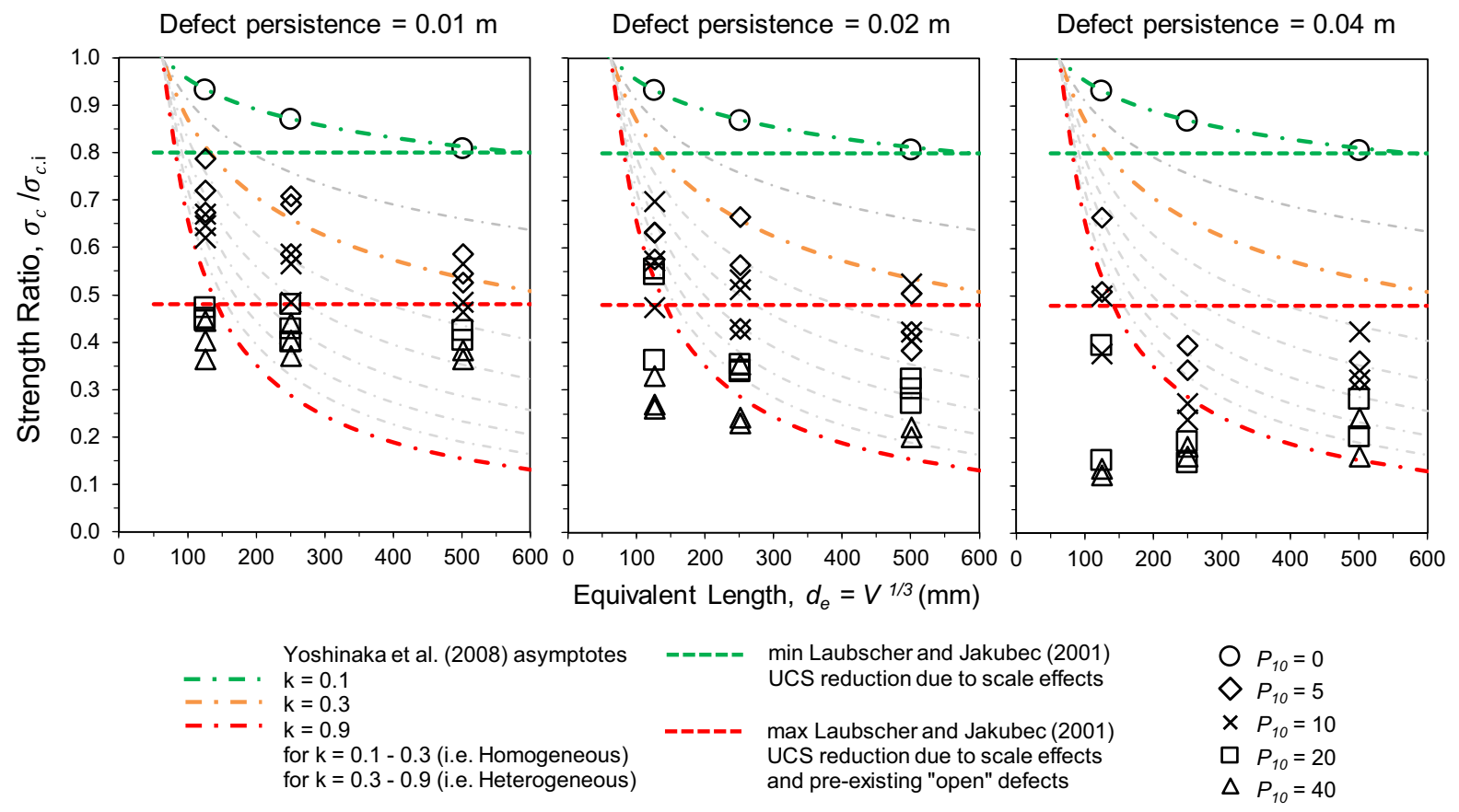

Fig. 13 Normalised UCS values as a function of sample size and $P_{10}$ defect intensity. Also shown for comparison are the Yoshinaka et al. (2008) and Laubscher and Jakubec (2001) strength limits

reductions which in turn are more consistent with the predicted UCS values from the SRB modelling. For low fracture frequencies (i.e. $P_{10}=5-101 / \mathrm{m}$ ) where the effect of specimen size appears important, the decreasing trend of UCS is similar in shape to the Yoshinaka et al. (2008) relations while for higher defect intensities (i.e. $P_{10}=20-401 / \mathrm{m}$ ) and defect continuities where strength drops rapidly and then reaches a constant value, an adjustment appears to be needed to capture the observed behaviour.

The results from the SRB scaling simulations were also plotted as a function of the $\mu \mathrm{DFN} P_{10}$ and $P_{21}$ defect intensities (Fig. 14). As expected, the reduction of UCS is more profound as defect frequency increases and defects persist. From a $P_{10}$ perspective (Fig. 14a), the inverse relationship between strength and defect frequency is not unique as four different envelopes delineate the strength decrease as a function of the four different defect lengths of $0.01 \mathrm{~m}, 0.02 \mathrm{~m}$, $0.04 \mathrm{~m}$ and $0.1 \mathrm{~m}$. A similar trend is also revealed when the data are plotted as a function of the $P_{21}$ intensity (Fig. 14b). Both Fig. 14a, b diagrams also reveal that the decay of strength follows a power-law trend and that beyond a certain defect intensity RBS remains relatively constant. However, it is important to note that the rate of strength reduction increases with an increase on defect persistence, meaning that strength reaches a constant behaviour at smaller fracture intensities as micro-defect length increases. From Fig. 14a, b it is also clear that, regardless of using the $P_{10}$ or $P_{21} \mu \mathrm{DFN}$ intensities, a systematic strength loss is observed for defect persistence of $0.01 \mathrm{~m}, 0.02 \mathrm{~m}$ and $0.04 \mathrm{~m}$ while for defect persistence of $0.1 \mathrm{~m}$ the magnitude of strength reduction has been reduced remarkably, suggesting that strength approaches a horizontal asymptote corresponding to a minimum strength in rock block scale. Because of this progressive strength reduction, when the defect intensities for each case are combined with the defect persistence (i.e. $P_{10}$ or $P_{21} \times$ Persistence), a very good clustering of the obtained values is observed in the data set and a unique solution appears to exist when the UCS ratio is plotted against the "Defect Intensity $\times$ Persistence-(DIP)" factor (Fig. 14c, d). The general trend of the data shown in Fig. 14c, $d$ is encouraging and suggests that the combination of defect intensity with defect persistence is adequate to express the strength of rock blocks under different geometrical scenarios and defect arrangements. 
(a)

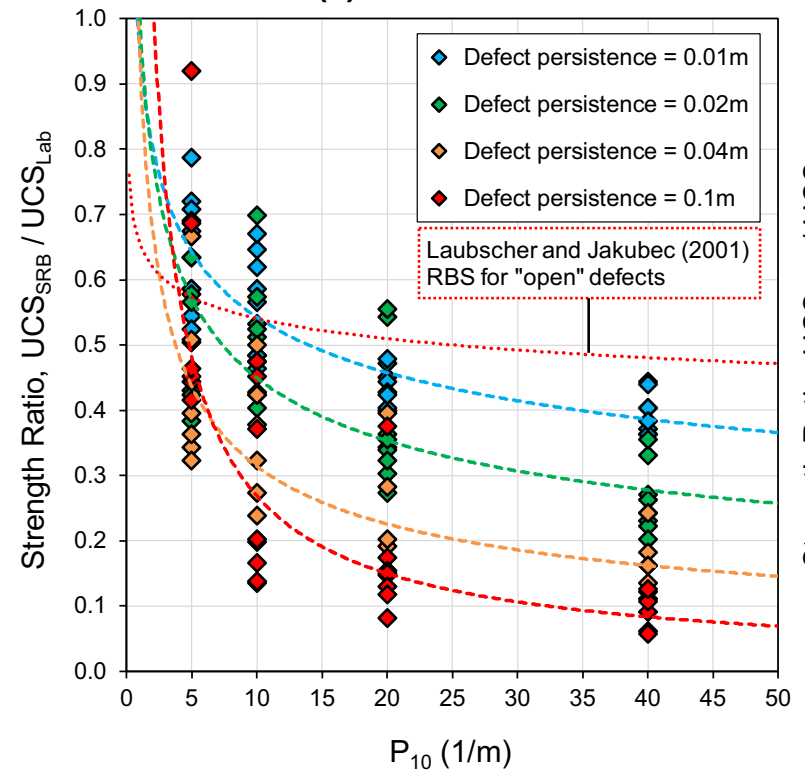

(b)

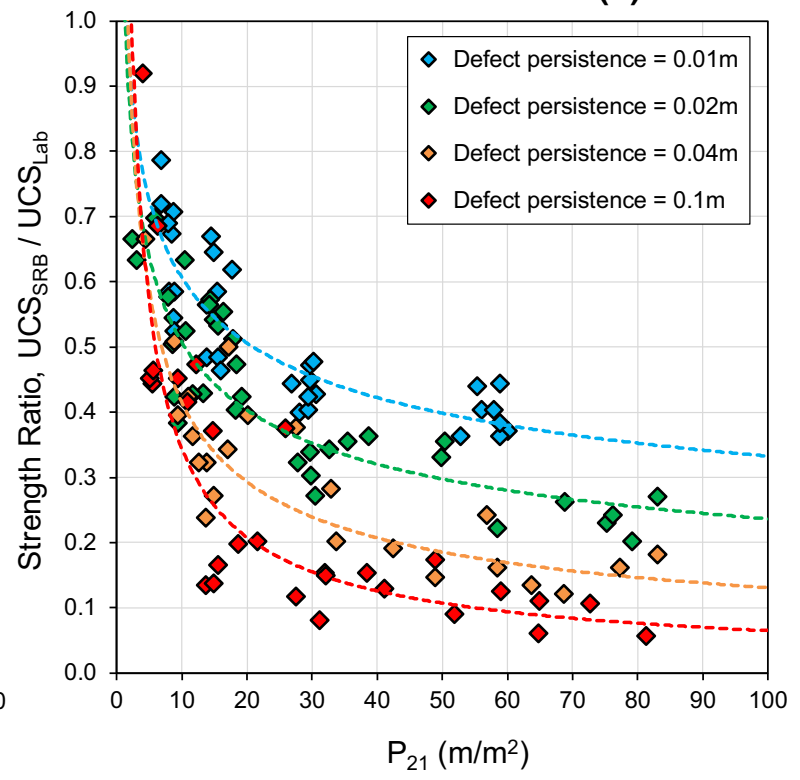

(c)

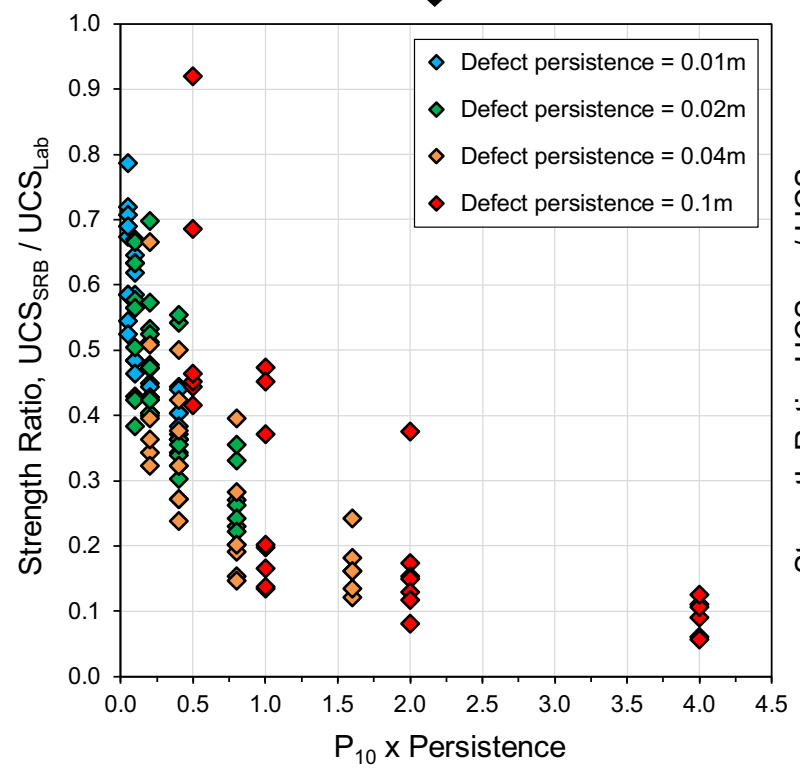

Fig. 14 a, b Normalised UCS values as a function of defect intensity $\left(P_{10}\right.$ and $\left.P_{21}\right)$ and defect persistence. Also shown for comparison is the rock block strength reduction for "open"

In Fig. 15, the predicted UCS values from the current study (Fig. 14) were plotted together with results from other numerical investigations for comparison. All studies, show a systematic decrease in the UCS with increasing degree of micro-fracturing, but
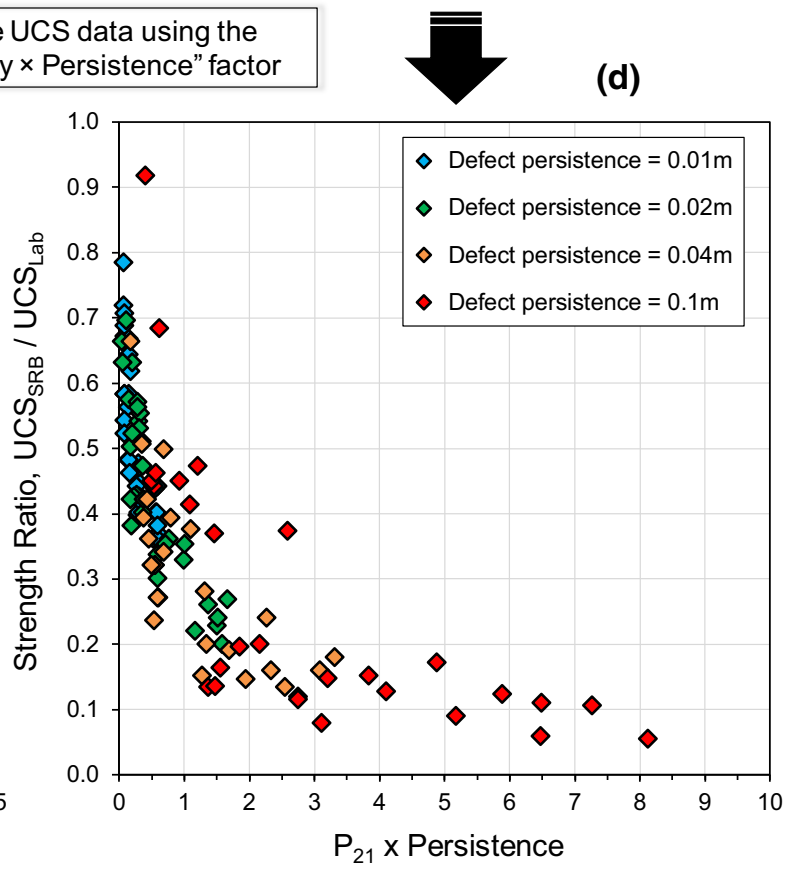

defects proposed by Laubscher and Jakubec (2001). c, d Normalised UCS values as a function of the "Defect Intensity $\times$ Persistence-(DIP)" factor

the shape/rate of the strength reduction illustrates clear discrepancies. The data of this study are in perfect agreement with Gao and Kang (2016), partially in agreement with $\mathrm{Lu}$ (2014) for large $P_{21}$ values, but differed from the findings of Hamdi et al. (2015). Lu 
Fig. 15 Comparison of predicted UCS results from current study with other numerical investigations examining scaling effects (Elmo and Stead 2010; Lu 2014; Hamdi et al. 2015; Gao and Kang 2016; Vazaios et al. 2018)

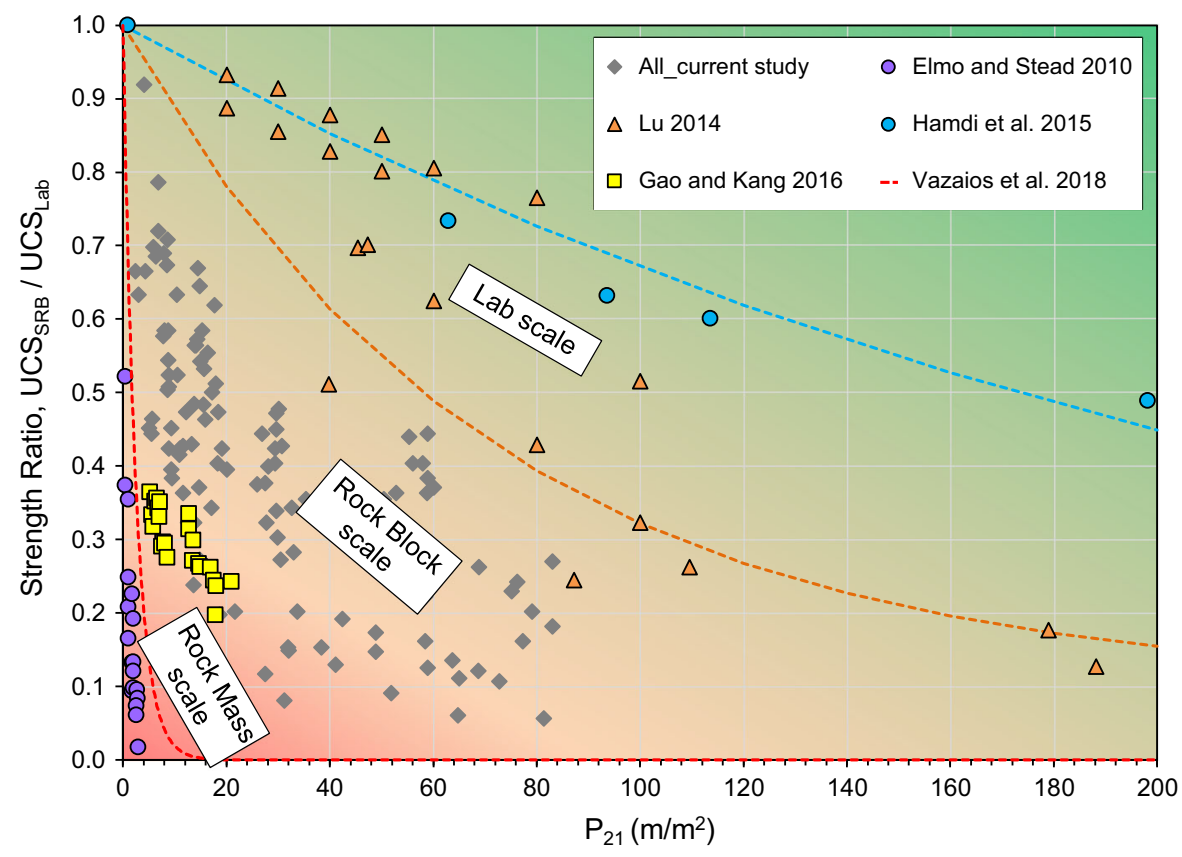

(2014) and Hamdi et al. (2015) considered in their studies small laboratory scale samples with crack lengths $15 \pm 1 \mathrm{~mm}$ and less than $1 \mathrm{~mm}$ respectively while Gao and Kang (2016) simulated larger block volumes (i.e. $300 \times 600 \mathrm{~mm}$ ) with defect persistence of $60 \pm 20 \mathrm{~mm}$. The Hamdi et al. (2015) work considers heterogeneities in the grain scale, the influence of which has already been accounted in our study by adopting the Laubscher and Jakubec (2001) $80 \%$ size factor (i.e. $80 \%$ of the baseline intact UCS). The good agreement with the results from Lu (2014) for large $P_{21}$ intensities and the identical results of Gao and Kang (2016) indicate again that variations in specimen size and defect length have a clear impact on the strength of rock blocks, the rate of strength loss and the resulting REVs. This observation is further supported in Fig. 15 by including two rock mass scale SRM studies (Elmo and Stead 2010; Vazaios et al. 2018) which demonstrate even more dramatic strength decrease rates, as expected, hence validating the general trend of strength reduction from small to large rock volumes with increasing defect populations and defect persistence.

\subsubsection{Influence of Defect Strength}

The analyses conducted in the previous section for the "open" defects demonstrated the significant effect of defect intensity and persistence on the strength of rock blocks. Further numerical simulations were undertaken to assess the impact of defect strength for the previously generated SRB models with micro-defect persistence values of $0.01 \mathrm{~m}$ and $0.04 \mathrm{~m}$ respectively. A parametric analysis was employed in which defect strength (i.e. cohesion and tension) was increased by $50 \%$ and $100 \%$ in respect to the size-corrected Voronoi interface strengths for the non-defect samples shown in Table 2 (hereafter referred as "baseline intact rock strength") while the stiffness values were assigned to be equal to the intact rock interface contacts (Table 4). Figure 16 exhibits the predicted UCS values in respect to the sample equivalent length $\left(d_{e}\right)$, the $\mu \mathrm{DFN}$ intensity $P_{10}$ and the defect strength. These findings are in agreement with similar studies conducted by Pierce et al. (2009) and Jakubec et al. (2012) who used the SRM method to study the combined effect of micro-defect strength and size on the UCS of rock blocks. The variation of UCS for the SRB samples with defect lengths of $0.01 \mathrm{~m}$ coincides reasonably well with the Yoshinaka et al. (2008) asymptotes but a less good fit is found for the samples with defect persistence of $0.04 \mathrm{~m}$. This is because the behaviour of the samples is not driven by the intact rock material in between the defects and the UCS reaches rapidly a constant strength even from the smaller samples. Nevertheless, these results suggest 


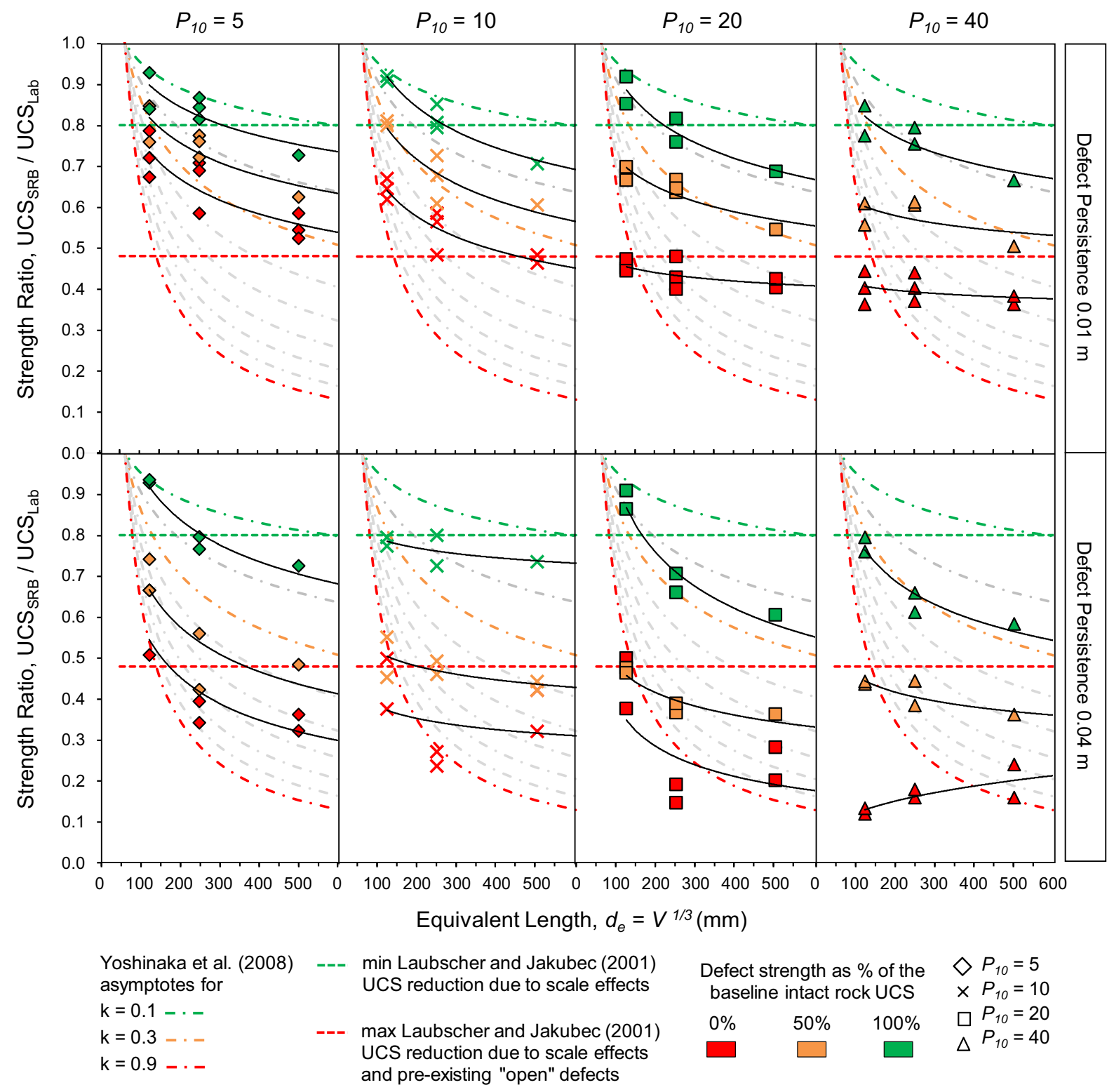

Fig. 16 Normalised UCS values as a function of sample size and $P_{10}$ defect intensity. Also shown for comparison are the Yoshinaka et al. (2008) and Laubscher and Jakubec (2001) strength limits

that in the case of non-highly persistent micro-defects, the exponent $k$ in the Yoshinaka et al. (2008) relationship could be expressed in terms of sample size and defect intensity $P_{10}$.

All results were also plotted together with the predicted UCS values for defect strength of $0 \%$ ("open" defects) as a function of the $P_{10}$ and $P_{21}$ defect intensities and are illustrated in Fig. 17. The progressive increase in defect strength from $0 \%$ to
$100 \%$ of the baseline intact rock strength improves significantly the UCS of the simulated samples as the micro-cracks are "locked" and their effect becomes less important (for the $50 \%$ defect strength) or even vanish (for the $100 \%$ defect strength). As can be seen in Fig. 17, the rate of gain in UCS for the SRB samples with defect persistence of $0.04 \mathrm{~m}$ is faster than the strengthening rate of samples with persistence of $0.01 \mathrm{~m}$, meaning that the shear strength of defects 
Table 4 Defect interface assigned properties in respect to the calibrated "baseline intact rock strength" micro-mechanical properties for the large-scale non-defected samples

\begin{tabular}{|c|c|c|c|c|c|c|c|c|c|c|c|}
\hline \multirow[t]{3}{*}{ Defect properties } & & & \multicolumn{9}{|c|}{ Sample size $(\mathrm{mm})$} \\
\hline & & & \multicolumn{3}{|c|}{$100 \times 250$} & \multicolumn{3}{|c|}{$200 \times 500$} & \multicolumn{3}{|c|}{$400 \times 1000$} \\
\hline & & & $0 \%$ & $50 \%$ & $100 \%$ & $0 \%$ & $50 \%$ & $100 \%$ & $0 \%$ & $50 \%$ & $100 \%$ \\
\hline Cohesion & $c_{d}$ & $\mathrm{MPa}$ & 0 & 5.65 & 11.3 & 0 & 5.35 & 10.7 & 0 & 4.7 & 9.4 \\
\hline Friction angle & $\varphi_{d}$ & {$\left[{ }^{\mathrm{o}}\right]$} & 47.5 & 47.5 & 47.5 & 46.2 & 46.2 & 46.2 & 42.4 & 42.4 & 42.4 \\
\hline Tensile strength & $t_{d}$ & $\mathrm{MPa}$ & 0 & 1.65 & 3.3 & 0 & 1.65 & 3.3 & 0 & 1.65 & 3.3 \\
\hline \multirow[t]{2}{*}{ Notes } & 1 & \multicolumn{10}{|c|}{ The $0 \%$ defect strength properties refer to the "open defects" modelled in Sect. 4.3.1 } \\
\hline & 2 & \multicolumn{10}{|c|}{$\begin{array}{l}\text { The } 100 \% \text { defect strength properties are equal to the size-corrected Voronoi interface strength properties for } \\
\text { non-defected samples shown in Table } 2\end{array}$} \\
\hline
\end{tabular}

overrides the effect of persistence as defect strength increases. This is more obvious at the scenario with defect strength equal to $100 \%$ of the baseline UCS where the strength of both samples has approached the scaled non-defected intact rock condition (i.e. $80 \%$ of the lab scale UCS) and the effect of persistence has essentially disappeared.

Figure 17 also includes the Laubscher and Jakubec (2001) relations for three different defect strengths ranging in the Mohs hardness index from 1 ("open" defects) to 5 (e.g. apatite and quartz). These limits define the lower and upper bounds for the defect frictional properties given in the MRMR system (Laubscher and Jakubec 2001). The Laubscher and Jakubec (Laubscher and Jakubec 2001) curves appear relative insensitive to the defect strength as the UCS increases by only $7-8 \%$ when defect strength increases from 1 to 5 for the complete range of micro-crack frequencies. On the other hand, the peak strengths attained by the SRB modelling suggests an increase in between $20-40 \%$ and $35-65 \%$ for the defect lengths $0.01 \mathrm{~m}$ and $0.04 \mathrm{~m}$ respectively. This observation is schematically illustrated in Fig. 18. However, a direct comparison between our findings and the Laubscher and Jakubec (2001) method is not possible at this stage.

Turichshev and Hadjigeorgiou (2017) demonstrated in their study that the peak strength of laboratory scale defected samples is strongly influenced by the vein mineralogy and thickness. For specimens with high volumetric content of "hard" minerals (i.e. Mohs hardness index $>4$ ) the authors found that the resulted strengths are higher by approximately $25 \%$ from specimens with high content of "soft" minerals (i.e. Mohs hardness index $<4$ ). These findings agree quite well with the UCS predictions from the SRB modelling performed in the current study. On the contrary, from an extensive laboratory dataset of different types of heterogenous rock samples with vein infilling ranging in Mohs hardness scale from 2 to 4, Bewick et al. (2018) found that vein hardness played relatively minor role on the resulting UCS values supporting the nomogram developed by Laubscher and Jakubec (2001). Although there is limited data available, the studies from Turichshev and Hadjigeorgiou (2017) and Bewick et al. (2018) possibly support the existence of a mineral hardness threshold of 4 that has been previously suggested by Brzovic and Villaescusa (2007). Regardless of these findings, as has been highlighted by Jakubec and Esterhuizen (2007), the proposed Mohs hardness scale for estimating the defect infill strength is only an empirical approach, and an effort should be made to better understand the strength contribution of these defects by means of laboratory experiments (e.g. Day et al. 2017) and/or SRM modelling (e.g. Pierce et al. 2009).

\subsection{Predicted Rock Block Young's Modulus}

From the conducted UCS experiments in UDEC, the Young's modulus at $50 \%$ of peak strength was also obtained to examine the effect of the pre-existing defects on the deformability of the synthetic models. Figure 19 demonstrates the predicted Young's modulus values from the SRB samples normalised in 

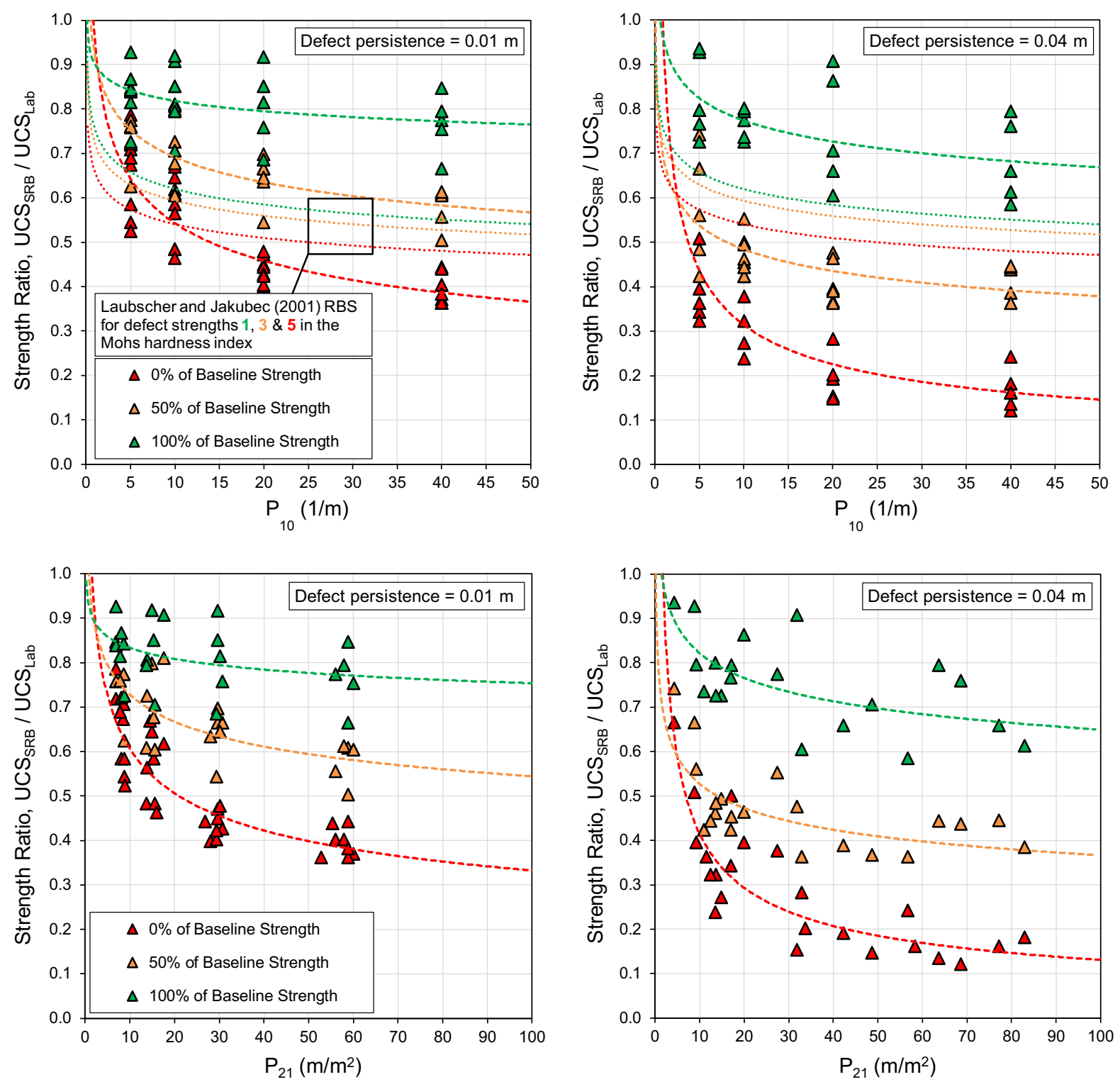

Fig. 17 Normalised predicted UCS values as a function of defect intensity $\left(P_{10}\right.$ and $\left.P_{21}\right)$ and defect strength. Also shown for comparison are three progressive rock block strength

respect to the intact rock modulus of $20 \mathrm{GPa}$ and Fig. 20 illustrates the resulted Modulus Ratio (MR) (i.e. Young's modulus/UCS) from the SRB analyses normalised with the intact rock MR (i.e. $20 \mathrm{GPa} /$ $50 \mathrm{MPa}=400$ ).

For a defect persistence of $0.01 \mathrm{~m}$ and $0.02 \mathrm{~m}$, the obtained modulus is relatively insensitive to the size and the presence of the pre-existing cracks while for a defect persistence of $0.04 \mathrm{~m}$ and $0.1 \mathrm{~m}$, an significant

reductions proposed by Laubscher and Jakubec (2001) for Mohs hardness index 1, 3 and 5

reduction is observed due to the reduced influence of intact rock bridges in between adjacent defects. In general, the deformation modulus appears to experience less pronounced scale effects in comparison with the predicted UCS values, but both properties follow a similar power-law function. The fact that the deformation modulus and strength follow a different scale effect response is further supported in Fig. 20 which clearly shows an increase in MR with increasing 
Fig. 18 Average normalised UCS values for defect strength $0 \%, 50 \%$ and $100 \%$ of the baseline intact rock strength in comparison with rock block strength values predicted by the Laubscher and Jakubec (2001) method for Mohs hardness index 1, 3 and 5

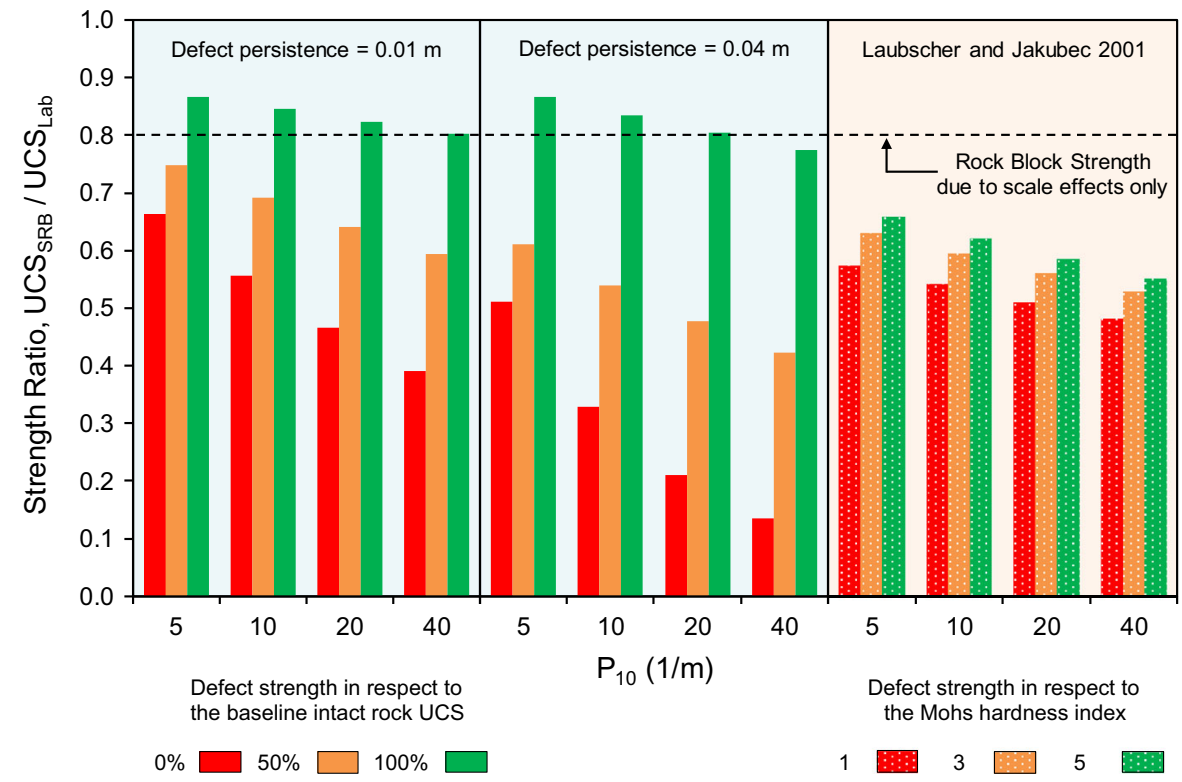

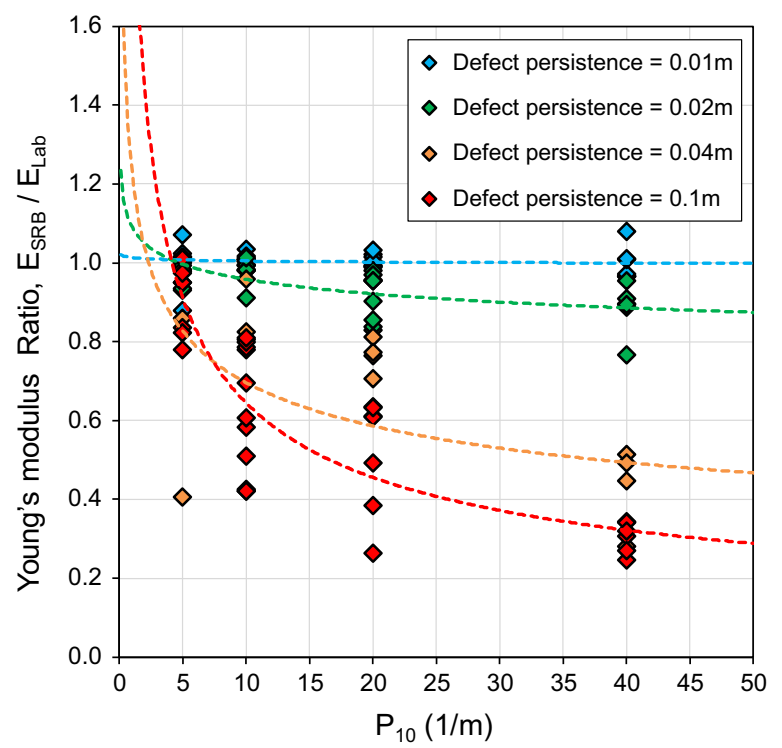

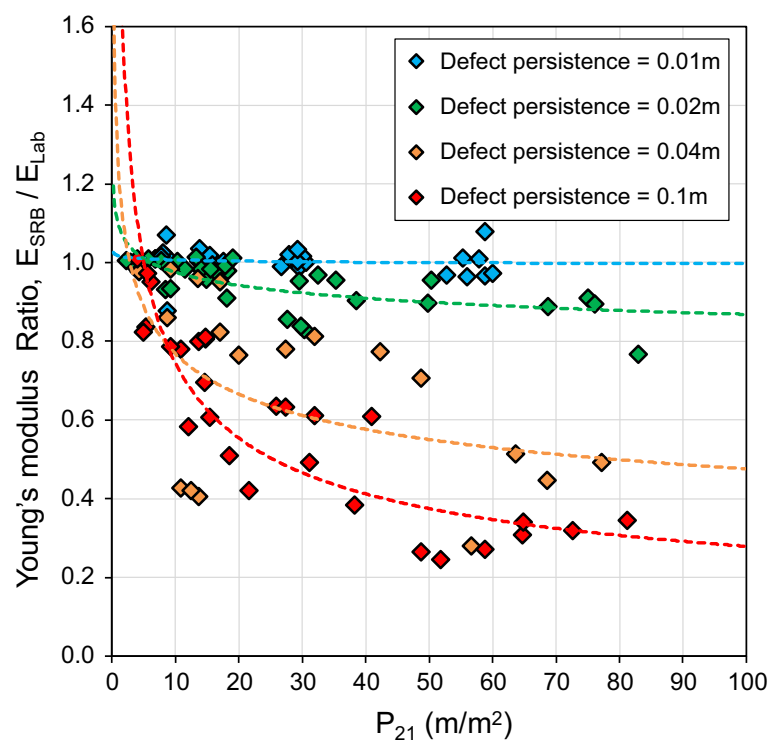

Fig. 19 Normalised Young's modulus values as a function of the defect intensity $\left(P_{10}\right.$ and $\left.P_{21}\right)$ and persistence

defect length and then a progressive decrease with increasing defect strength. This is because strength experiences more aggressive reductions than then modulus of elasticity and because the rate of modulus improvement is faster than the rate of strength increases when defect strength increase from $0 \%$ to $100 \%$ of the baseline intact rock strength.

To investigate a possible correlation between strength and stiffness, the predicted normalised UCS values from all cases were plotted against the associated normalised Young's modulus values (Fig. 21). Both parameters were normalised in respect to the lab scale strength and modulus respectively. As it can be observed, for UCS reductions up to $40 \%$, the elastic modulus remains essentially unchanged (i.e. Zone 1) and then for greater strength reductions, the Young's modulus departs from the intact rock behaviour and 

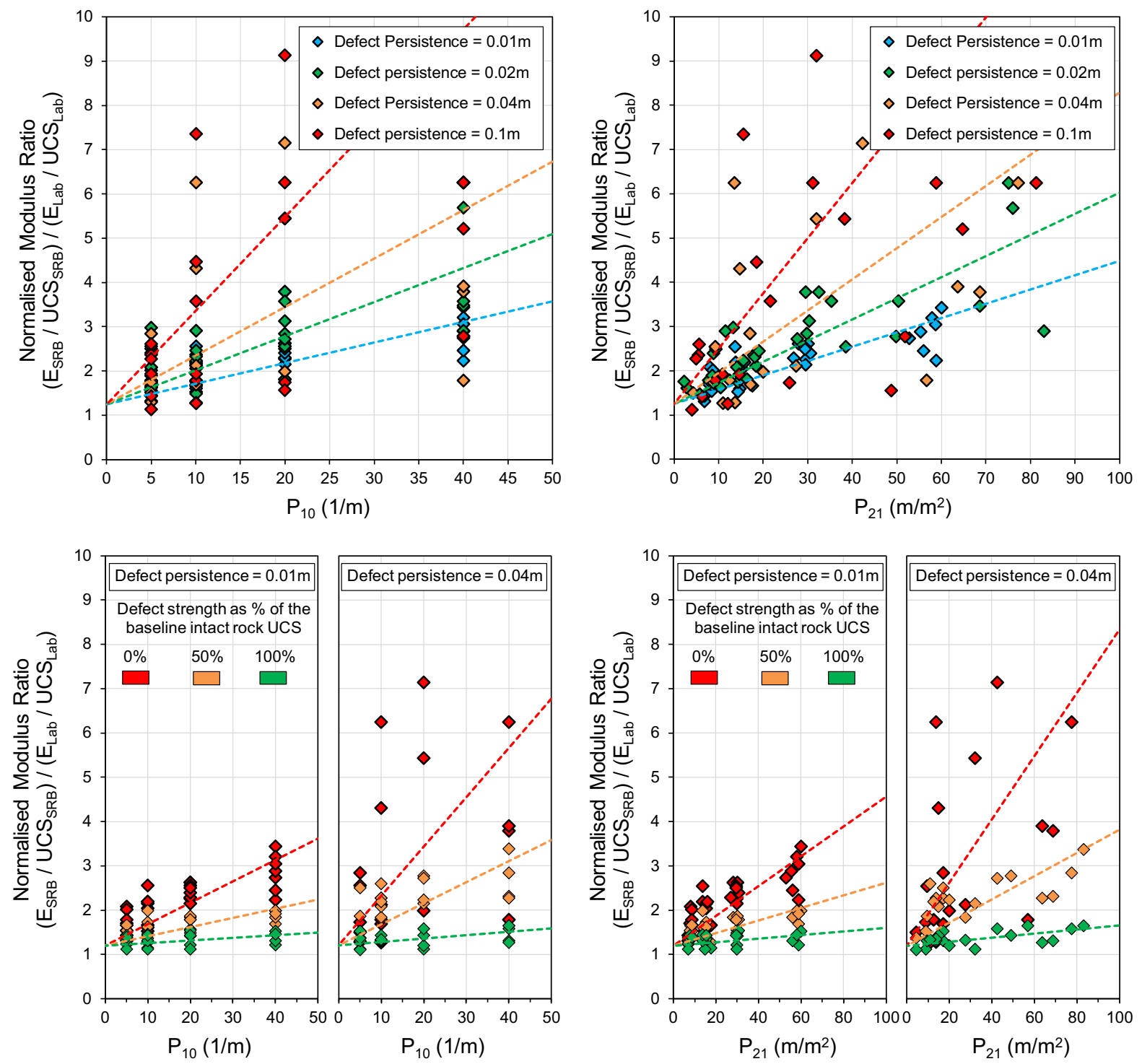

Fig. 20 Normalised Modulus Ratio (SRB MR/Lab MR) as a function of the defect intensity $\left(P_{10}\right.$ and $\left.P_{21}\right)$, persistence and strength

decreases rapidly as strength drops with decreasing intact rock quality (i.e. Zone 2).

Based on laboratory studies investigating scaling effects in rock block size, no major influence on the elastic modulus has been found as specimen size increases (Pratt et al. 1972; Singh and Huck 1972; Price 1986; Jackson and Lau 1990). The deformation modulus from these studies appear to remain relatively unaffected or to decrease up to $15 \%$ with changes in sample size. Although limited experimental data is available, the range of observed moduli from the SRB analysis results are consistent with the general admission that the Young's modulus is relatively independent of sample size.

\subsection{Observed Failure Modes}

The SRB simulations replicated successfully the failure processes that typically observed in actual laboratory experiments under unconfined conditions (i.e. crack initiation followed by crack propagation and coalescence resulting in unstable extensional fracturing parallel to the direction of loading). However, the presence of cohesionless pre-existing defects 


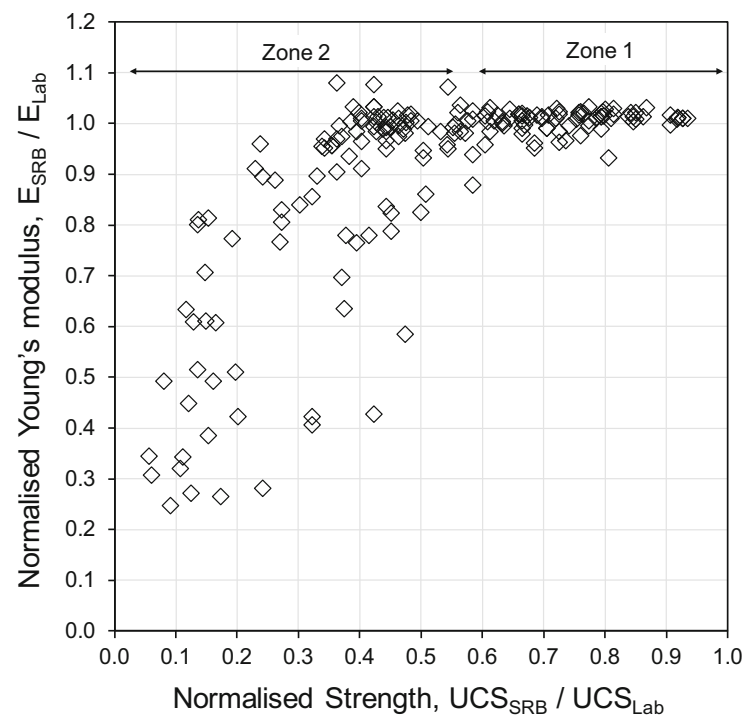

Fig. 21 Normalised Young's modulus values as a function of the defect intensity $\left(P_{10}\right.$ and $\left.P_{21}\right)$ and persistence

triggered distinctly different failure modes in comparison with the non-defected samples. Figure 22 illustrates the transition from an intact rock fracturing driven failure mechanism to a structurally controlled dominated damage. As observed, for the specimens containing defects, wing cracks are generated at the tips of the pre-existing flaws due to localised stress concentrations leading to unstable micro-fracturing and the formation of macroscopic bands. In contrast, for the non-defected specimens, failure typically initiates from the edges of the samples due to extensional microfracturing and then propagates inwards forming a double pyramid failure shape.

The contribution of the wing cracks in the overall strength reduction appears to increase as defect persistence increases due to the interaction of neighbouring defect tips which tend to attract each other. Regardless of the size and orientation of the preexisting defects, wing cracks propagate simultaneously from the upper and lower tips due to microtensile fracturing parallel to the direction of loading. Figure 23 summarises the typical failure modes observed for increasing defect intensity and persistence. For specimens with low fracture intensities, tensile localisation and splitting along the "grains" dominate the failure process, while for a higher degree of fracturing, crack propagation is significantly prohibited, and sample damage is clearly dependent on

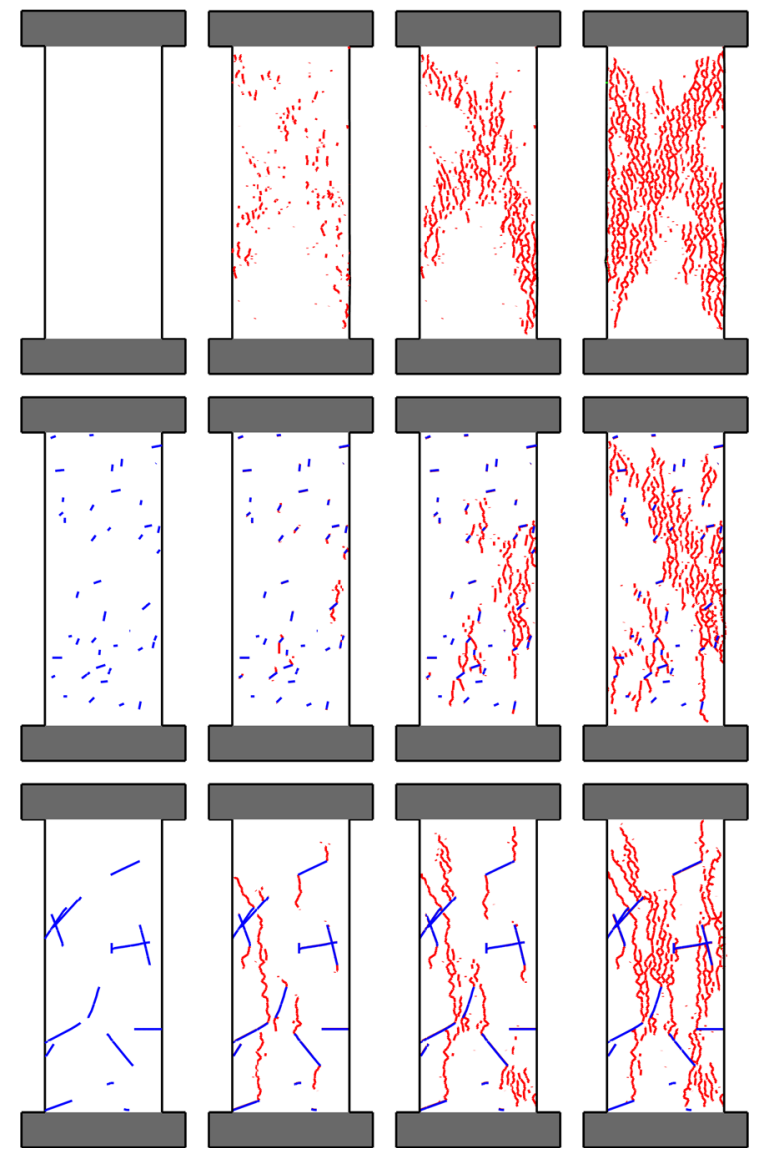

Fig. 22 Evolution of damage and typical failure modes captured for the intact non-defected (above) and defected (middle and below) SRB samples. The lines with blue colour denote failed pre-existing defects while those with red represent newly generated micro-cracks

the failure of the pre-existing defects. From Fig. 23 it can be inferred that samples with smaller intact rock bridges are more likely to fail at lower stress magnitudes, with the extent of reduction being closely dependent on the persistence of pre-existing defects.

Regarding the response of the samples as defect strength increases from 0 to $50 \%$ and then $100 \%$ of the baseline intact rock strength, defect strength is proven to be a dominant factor controlling the failure mode of the SRB samples. In Fig. 24, initially it can be observed that as the pre-existing defect strength increases from $0 \%$ (purely frictional defects) to $100 \%$ (defects with cohesion and tensile strength equal to Voronoi block interfaces) a progressive increase in the specimen strength to that of the intact sample is achieved, as expected. By examining the 


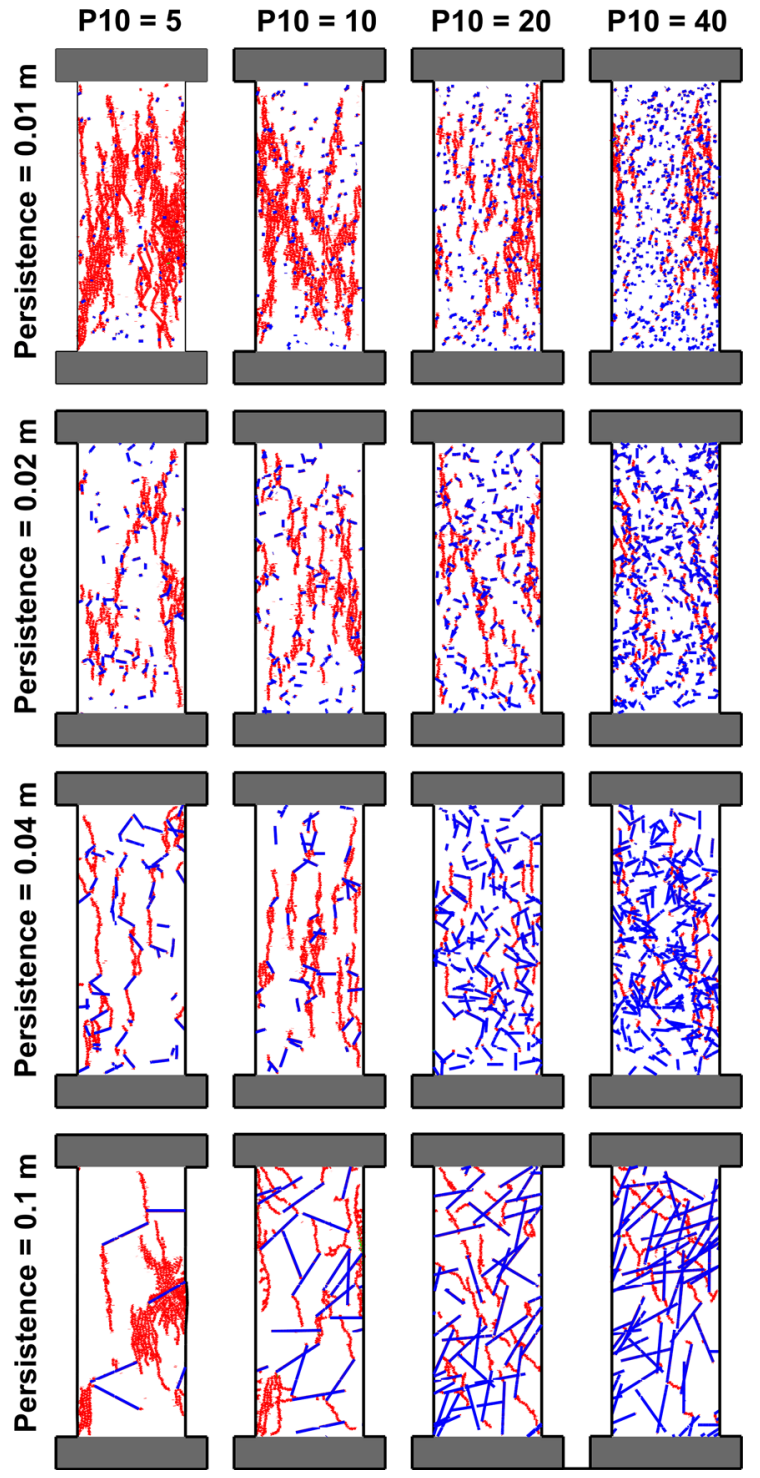

Fig. 23 Failure modes for progressively increasing defect intensities and defect persistence. The lines with blue colour denote failed pre-existing defects while those with red represent newly generated micro-cracks

lateral and volumetric strain curves, this increase in material strength can be directly related to the strain capacity of the sample which also increases by improving the defect condition. More specifically, for the case of $0 \%$ defect strength, both the lateral and volumetric strains follow a stepped path due to the stress localization at the defect tips, promoting the creation of wing cracks, and subsequently the fracturing of intact rock bridges before the complete failure of the sample. This is confirmed by the crack monitoring scheme employed. From it, it becomes evident that as rock bridges fail a temporary stable condition is achieved before the next rock bride breaks as indicated by the crack number remaining constant for a short period of time (short plateaus appearing in the broken contact curve). By increasing the defect strength to $50 \%$, a partially similar response can be observed. However, as a result of the increased defect strength, pre-existing discontinuities become harder to fail, stress localization at the defect tips is reduced, and new cracks involve both the generation of wing cracks at the defect tips and axial cracks initiating at the Voronoi block edges within the intact parts of the sample. For the case where Voronoi and defect strength interfaces are the same, the sample response is not governed by the failure of rock bridges. On the contrary, cracks forming parallel to the load direction (axial cracks) start appearing in the specimen until they reach a critical density and the specimen fails having distinct shear bands (Fig. 24). This transition of the generated new cracks from wing to axial fractures results in an increased strain capacity of the sample (the sample can contract more) before failing, and a more abrupt (brittle) failure occurs. On the contrary, for lower defect strengths this occurs in a more gradual, progressive fashion as described above due to the distinct rock bridges breaking.

\section{Refined Approaches for RBS Estimation}

The results of the SRB numerical study are encouraging as certain trends were observed in the UCS reduction in respect to the sample size, defect intensity, persistence and strength. Based on our findings, we attempt to extent the empirical relationships given by Laubscher and Jakubec (2001) and Yoshinaka et al. (2008), and modified correlations are proposed for estimating the strength of defected rock blocks.

The empirical relation of Laubscher and Jakubec (2001) (Fig. 2) considers the influence of specimen scale, and the impact of defect frequency together with the defect infill hardness. Extending this logic, Fig. 25 presents a series of charts that express rock block strength as function of sample size, defect intensity, defect persistence and defect strength. In these charts, the fracture intensity (either $P_{10}$ or $P_{21}$ ) from the various modelling scenarios has been combined with the persistence of each case (i.e. the DIP factor) to 


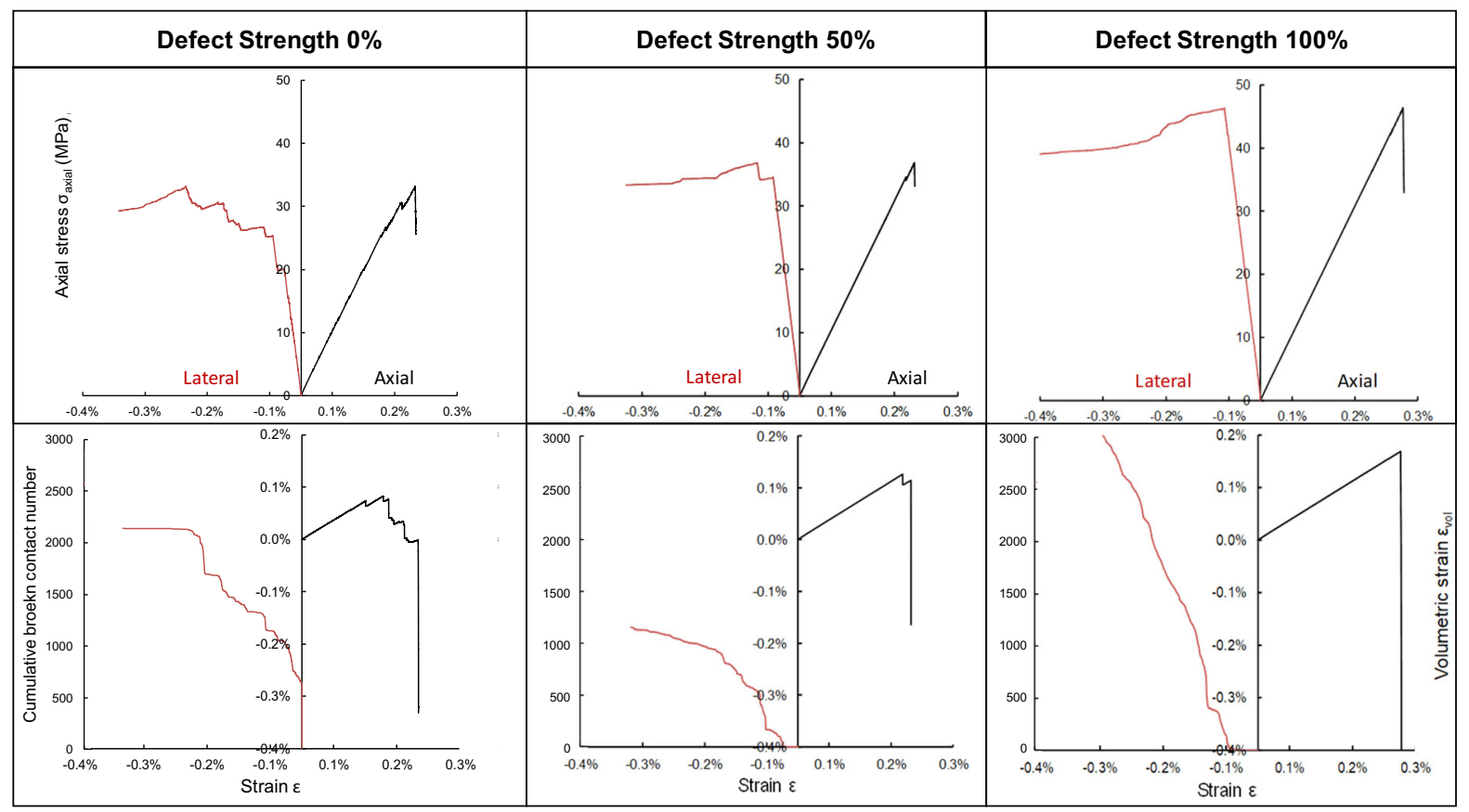

Fig. 24 Specimen $100 \times 250 \mathrm{~mm}$ for $P_{10}=51 / \mathrm{m}$ and defect length $0.04 \mathrm{~m}$ : Typical stress-axial/lateral strain (above), volumetric — axial strain and crack count—lateral strain (below)

standardise the data variability into one unique solution and to allow for flexibility in the UCS predictions over a wide range of defect geometries and defect strengths. The same inverse strength relationships are presented into three different diagrams to magnify specific defect geometrical regions which otherwise would have been difficult to visualise if were plotted into the same chart.

The proposed charts incorporate all the essential factors controlling the unconfined strength of rock blocks. Defect strength can be assessed by empirical approaches such as drop testing of the core during logging or by the hammer blow test. Core breaks along pre-existing defects during drilling can also provide an indication about the nature of the micro-defects and their possible contribution to rock block strength. Classification of failure modes (e.g. "intact", "structural", "combined" failure types) from UCS and triaxial lab testing has also been proven as an effective method to estimate the shear strength of specific defects from samples that have failed along preexisting planes of weakness (Bewick et al. 2018). Furthermore, back-analysis of laboratory experiments using synthetic rock block samples can be used to curves showing the transition in the failure mode as defect strength increases from $0-50-100 \%$ of the baseline intact rock strength

derive site-specific correlations and to investigate the mobilised shear strength of individual defects (Turichshev and Hadjigeorgiou 2017). By calibrating the micro-properties of non-defected and defected specimens it should be possible to derive the defect strength reduction as a function of the baseline intact rock grain-to-grain strength.

In terms of the geometrical inputs, defect intensity could be derived via logging explicitly the microdefects that occur along cores/scan-lines (1D observation), by sampling rock surface exposures (2D observation) or by using imaging techniques (e.g. Lidar or photogrammetry). Quantification of the defect length can be challenging due to the threedimensional character of the defects and restrictions in mapping the internal structure of rock blocks. Nevertheless, trace lengths measured as part of rock face mapping investigations can provide a reasonable approximation for the persistence. In case of microdefects macroscopically not visible by naked eye, then very small persistence values should be used but it should be reminded that the charts already contain a size correction allowance considering heterogeneity in 

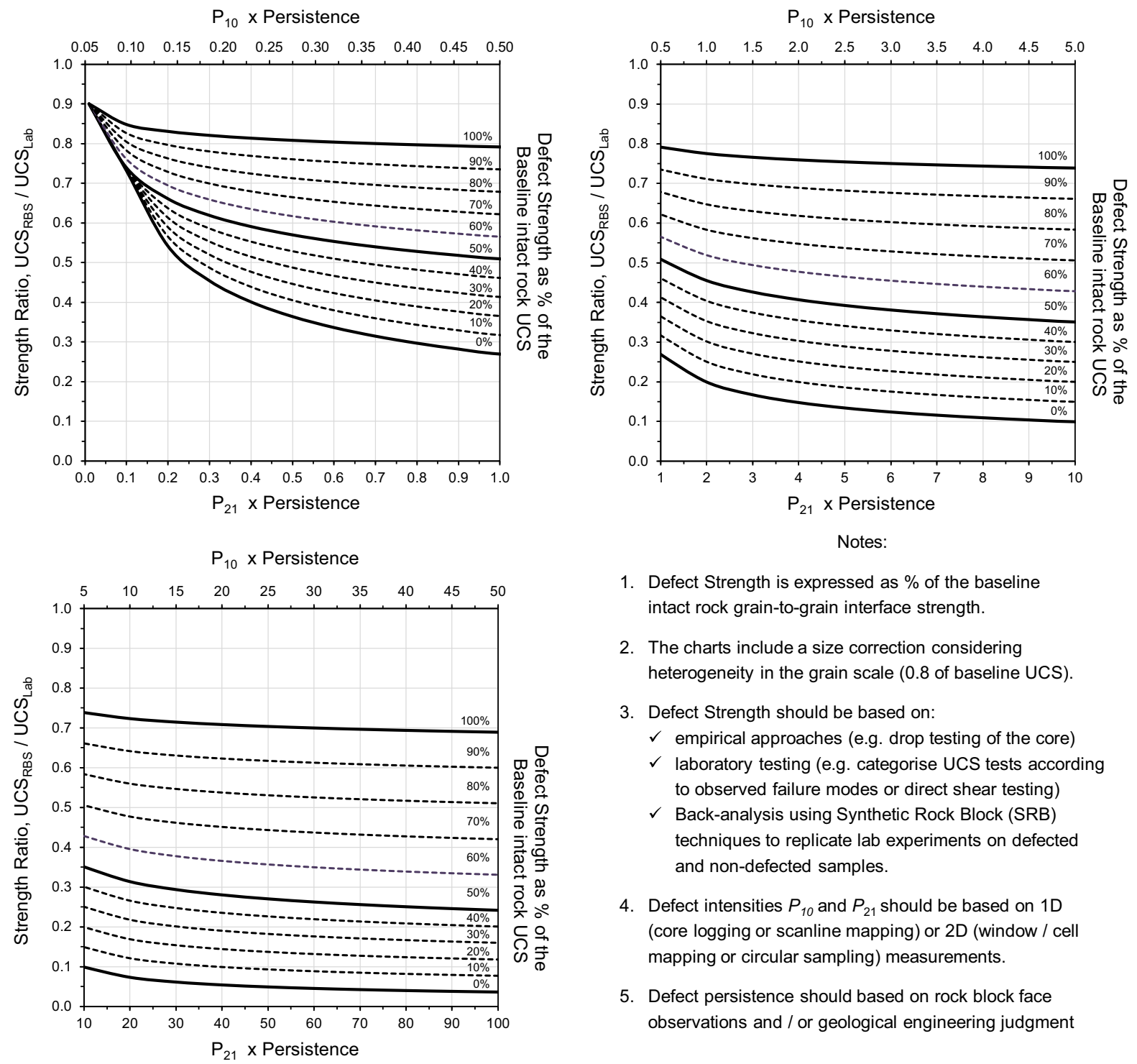

1. Defect Strength is expressed as $\%$ of the baseline intact rock grain-to-grain interface strength.

2. The charts include a size correction considering heterogeneity in the grain scale ( 0.8 of baseline UCS).

3. Defect Strength should be based on: $\checkmark$ empirical approaches (e.g. drop testing of the core)

$\checkmark$ laboratory testing (e.g. categorise UCS tests according to observed failure modes or direct shear testing)

$\checkmark$ Back-analysis using Synthetic Rock Block (SRB) techniques to replicate lab experiments on defected and non-defected samples.

4. Defect intensities $P_{10}$ and $P_{21}$ should be based on 1D (core logging or scanline mapping) or 2D (window / cell mapping or circular sampling) measurements.

5. Defect persistence should based on rock block face observations and / or geological engineering judgment

Fig. 25 Proposed diagrams for estimating the Rock Block Strength (RBS) as a function of defect intensity, persistence, and strength

the grain scale (i.e. contrasts in the geometrical or mechanical properties of grains).

In regard to the empirical scaling relationship from Yoshinaka et al. (2008), although it allows for a wide range of UCS predictions, the results from our numerical study found poor correlations between size, defect geometries and strength. As a consequence, a calibration of the exponent $\mathrm{k}$ was no attempted, although theoretically it can be back-calculated using the diagram shown in Fig. 25.

\section{Discussions}

It is widely recognised that the UCS of intact rock decreases with increasing scale and/or increasing micro-defect intensity due to size effects and the reduced intact rock bridges in between the defects (e.g. grain boundaries, cavities, fissures, veins and open or healed micro-cracks, etc.). However, apart from two empirical approaches (i.e. Laubscher and Jakubec 2001; Yoshinaka et al. 2008) that consider the effect of scale and micro-defects to evaluate the strength of rock blocks, the available guidelines are limited, and 
more rigorous methodologies are required to obtain representative rock block strength parameters. Yoshinaka et al. (2008) proposed a scaling relationship that can capture the inverse relationship of strength for a wide range of the in situ rock block conditions but the authors do not provide guidelines on how to apply their methodology based on qualitative or quantitative approaches. On the other hand, the empirical methodology of Laubscher and Jakubec (2001) provides a clear pathway on how to assess rock block strength based on size and defect conditions adjustments but their relation offers predictions for a limited range of strength reductions.

In this context, a numerical study was performed to examine the combined effect of sample size and defect conditions (i.e. intensity, persistence and strength) on the strength of rock blocks. Several UCS tests were conducted on synthetic rock block samples of varying sizes and defect geometries/strengths as an attempt to develop a framework for assessing the strength of defected rock blocks. The results from these experiments were compared with previous studies and the existing empirical relationships, and refined approaches are proposed for estimating the unconfined strength of rock blocks as a function of specimen size, defect intensity, persistence and strength.

The predicted UCS values were found to be strongly influenced by both size and defect condition effects while the Young's modulus appeared to be less sensitive. Nevertheless, both properties appear to follow a power-law distribution that eventually reaches a plateau for large samples sizes and/or closely spaced defects and/or highly persistent defects. Analysis of the large-scale UCS tests revealed that there is a systematic and progressive strength reduction with decreasing intact rock quality in terms of defect intensity, persistence and strength. When the fracture intensity (either $P_{10}$ or $P_{21}$ ) from the various modelling scenarios was combined with the persistence of each case, all data followed certain paths for the analysed defect strengths. This allow us to standardise the data along specific strength reduction envelopes and to propose generic predictive diagrams that cover a wide range of defect geometrical combinations and strengths. The use of the "Defect Intensity $\times$ Persistence" or DIP factor is likely to be transferable to larger scales and rock mass classifications systems that currently consider only the blockiness of rock masses and not the effect of nonpersistent discontinuities.

Currently, defect strength is expressed as percentage of the intact size-corrected grain-to-grain strengths and although further research is required to rationalise this parameter, the use of synthetic rock block modelling techniques can be used to define lower and upper bounds. Despite of these difficulties, it is to be expected that strong defects can result in blocks behaving essentially as an intact material while weaker defects can cause dramatic strength reductions and changes on the failure modes. In addition, defect micro-persistence is unlikely to be constant for a given rock type and an effort should made to derive an equivalent defect length from the anticipated size distributions. Since micro-defect populations are typically developed at similar conditions and possibly simultaneously with the large-scale discontinuities, analysis of the macro-fracture patterns can also be used as an indicator for the geometrical assessment of defects.

It is important to mention that careful consideration is required to establish characteristic lab-scale intact rock strengths when using the proposed approaches as underestimation or overestimation of the baseline UCS will influence the predictions for rock block strength. Sampling bias on favour of the better in quality sections of core may result in overestimating the intact rock strength while material disturbance due to drilling/handling damage or stress relief and microcracking are the most common reasons to underpredict strength. To overcome these uncertainties, it is suggested to narrow the large scatter of results by classifying the UCS test data based on the observed failure methods (i.e. homogeneous versus heterogeneous samples) and by performing statistical analysis to assess the variability of the data for each group.

\section{Conclusions}

Rock block strength is a significant factor controlling the rock mass behaviour (i.e. deformations, failure modes, fragmentation, stand-up time, etc.) and the response of the structural elements used as rock support and rock reinforcement. For massive to moderately jointed rock masses with incomplete discontinuities and/or high degree of interlock between the rock blocks, rock mass failure cannot 
occur without fracturing through rock blocks. Hence, it is vital to assess the strength of blocks as accurately as possible.

Especially when the design relies on discontinuum analysis where rock blocks are modelled explicitly as equivalent continuum materials in between discontinuities, rock block properties are a dominant driver influencing the results and the specification of reinforcement solutions and construction stages.

Several case-studies have highlighted the importance of considering the effect of pre-existing defects within the rock material but typically, the role of defects is neglected when evaluating the strength of rock blocks and rock masses. This can lead to misleading evaluations and implications on i) health and safety issues (e.g. instabilities, injuries/fatalities); ii) a sequence of design decisions (e.g. support measures, construction methods and sequence); and iii) project economics (e.g. delays, loss of production and claims).

In the current study, an extensive numerical analysis was performed using synthetic specimens composed by micro-mechanical elements and discrete fracture networks and relationships that link the UCS of rock blocks with its size and the geometrical arrangement and strength of defects were developed. Previous work by Stavrou and Murphy (2018) proposed linear and non-linear scaling relationships for estimating the confined strength of rock blocks, provided that the UCS reduction due to scaling effects is known. The combination of the current work (for estimating the unconfined strength of rock blocks) and the previous work by Stavrou and Murphy (2018) (for estimating the confined strength of rock blocks) offers the full suite of relationships needed to determine a complete set of design properties at a rock block scale.

Although further research is required to validate the proposed approaches against actual laboratory experiments or in situ monitoring data and back-analysis, the results showed how the impact of the pre-existing cracks can be quantified to relate the strength of rock blocks with specific measurable quantities. The study is therefore highlighting the strong potential of using synthetic rock mass modelling techniques to develop quantitative guidelines, to refine empirical relationships and to update rock mass classification systems.

Acknowledgements The authors would like to thank ARUP for financially supporting this research. We would also like to thank Dr. Mark S. Diederichs for his guidance and meaningful discussions and James Woodman for matters concerning numerical modelling.

Open Access This article is distributed under the terms of the Creative Commons Attribution 4.0 International License (http:// creativecommons.org/licenses/by/4.0/), which permits unrestricted use, distribution, and reproduction in any medium, provided you give appropriate credit to the original author(s) and the source, provide a link to the Creative Commons license, and indicate if changes were made.

\section{References}

Baecher GB (1983) Statistical analysis of rock mass fracturing. J Int Assoc Math Geol 15(2):329-348

Bahrani N, Kaiser PK (2016) Numerical investigation of the influence of specimen size on the unconfined strength of defected rocks. Comput Geotech 77:56-67

Bewick RP, Kaiser PK, Amann F (2018) Strength of massive to moderately jointed hard rock masses. J Rock Mech Geotech Eng [Internet]. http://www.sciencedirect.com/ science/article/pii/S1674775518303986. Accessed 15 Jan 2019

Bieniawski ZT (1968) The effect of specimen size on compressive strength of coal. Int $\mathrm{J}$ Rock Mech Min Sci 5(ii):325-335

Brzovic A, Villaescusa E (2007) Rock mass characterization and assessment of block-forming geological discontinuities during caving of primary copper ore at the El Teniente mine, Chile. Int J Rock Mech Min Sci 44(4):565-583

Carpinteri A (1994) Fractal nature of material microstructure and size effects on apparent mechanical properties. Mech Mater 18(2):89-101

da Cunha AP (1990) Scale effects in rock masses. In: Pinto da Cunha A (ed) Proceedings of the first international workshop on scale effects in rock masses, Loen, 7-8 June 1990. da Cunha AP, Mechanics IC on SE in R, editors. Published for the ISRM Commission on Scale Effects in Rock Mechanics by A.A. Balkema, Rotterdam

Damjanac B, Board M, Lin M, Kicker D, Leem J (2007) Mechanical degradation of emplacement drifts at Yucca Mountain-a modeling case study: part II: lithophysal rock. Int J Rock Mech Min Sci 44(3):368-399

Davy P, Le Goc R, Darcel C (2013) A model of fracture nucleation, growth and arrest, and consequences for fracture density and scaling. J Geophys Res Solid Earth 118(4):1393-1407

Day JJ, Diederichs MS, Hutchinson DJ (2017) New direct shear testing protocols and analyses for fractures and healed intrablock rockmass discontinuities. Eng Geol 229:53-72

Dershowitz WS, Einstein HH (1988) Characterizing rock joint geometry with joint system models. Rock Mech Rock Eng 21(1):21-51. https://doi.org/10.1007/BF01019674

Dershowitz WS, Herda HH (1992) Interpretation of fracture spacing and intensity. In: Rock mechanics

Dershowitz W, Lee G, Geier J, Foxford T, LaPointe P, Thomas A (2014) FracMan version 7.4-interactive discrete 
feature data analysis, geometric modeling, and exploration simulation: user documentation. Golder Associates, Redmond, Wash

Einstein HH, Baecher GB, Hirschfeld RC (1970) The effect of size on strength of a brittle rock. Int Soc Rock Mech Proc 2:7-13

Elmo D, Stead D (2010) An integrated numerical modellingdiscrete fracture network approach applied to the characterisation of rock mass strength of naturally fractured pillars. Rock Mech Rock Eng 43(1):3-19

Farahmand K, Vazaios I, Diederichs MS, Vlachopoulos N (2018) Investigating the scale-dependency of the geometrical and mechanical properties of a moderately jointed rock using a synthetic rock mass (SRM) approach. Comput Geotech 95:162-179

Gao FQ, Kang HP (2016) Effects of pre-existing discontinuities on the residual strength of rock mass - Insight from a discrete element method simulation. J Struct Geol 85:40-50

Gao FQ, Stead D (2014) The application of a modified Voronoi logic to brittle fracture modelling at the laboratory and field scale. Int J Rock Mech Min Sci 68:1-14

Gao F, Stead D, Kang H (2014) Numerical investigation of the scale effect and anisotropy in the strength and deformability of coal. Int J Coal Geol 136:25-37

Hamdi P, Stead D, Elmo D (2015) Characterizing the influence of stress-induced microcracks on the laboratory strength and fracture development in brittle rocks using a finitediscrete element method-micro discrete fracture network FDEM- $\mu$ DFN approach. J Rock Mech Geotech Eng 7:609-625

Hoek E, Brown T (1980) Underground excavations in rock. Taylor \& Francis, Boca Raton (Geotechnics and foundations)

Hoek E, Brown ET (1997) Practical estimates of rock mass strength. Int J Rock Mech Min Sci 34(8):1165-1186

Itasca U (2014) Version 6.0. Itasca Consult Gr Inc, Minneapolis

Jackson R, Lau JSO (1990) The effect of specimen size on the laboratory mechanical properties of Lac du Bonnet grey granite. In: da Cunha AP (ed) Proceedings of the 1st international workshop on scale effects in rock masses, Loen. AA Balkema, Rotterdam, pp 165-74

Jakubec J (2013) Role of defects in rock mass classification. Australian Centre for Geomechanics, pp 1-8

Jakubec J, Esterhuizen GS (2007) Use of the mining rock mass rating (MRMR) classification: industry experience. In: Mark C, Pakalnis R, Tuchman RJ (eds) Proceedings international workshop on rock mass classification in underground mining, Vancouver, National Institute for Occupational Safety and Health Information Circular (IC), pp 413-421

Jakubec J, Board M, Campbell R, Pierce M, Zaro D (2012) Rock mass strength estimate-Chuquicamata case study. In: MassMin 2012. Canadian Institute of Mining, Metallurgy and Petroleum (CIM), Sudbury

Kazerani T, Zhao J (2010) Micromechanical parameters in bonded particle method for modelling of brittle material failure. Int $\mathrm{J}$ Numer Anal Methods Geomech 34(18):1877-1895

Laubscher DH, Jakubec J (2001) The MRMR rock mass classification for jointed rock masses. Undergr Min Methods
Eng Fundam Int Case Stud WA Hustrulid RL Bullock Soc Min Metall Explor SMME, pp 475-481

Lim SS, Martin CD, Åkesson U (2012) In-situ stress and microcracking in granite cores with depth. Eng Geol 147:1-13

Lu Y (2014) Estimating rock strength of moderately fractured EDZ in hard rock tunnels: Äspö Hard Rock Laboratory. University of Alberta

Mas Ivars D, Deisman N, Pierce M, Fairhurst C (2007) The synthetic rock mass approach-a step forward in the characterization of jointed rock masses

Mogi K (1962) The influence of the dimensions of specimens on the fracture strength of rocks: comparison between the strength of rock specimens and that of the earth's crust

Nasseri MHB, Young RP, Rezanezhad F, Cho SH (2009) Application of 3D X-ray CT scanning techniques to evaluate fracture damage zone in anisotropic granitic rock. In: 3rd US-Canada rock mechanic symposium Toronto, pp 55-56

Palmstrom A (2005) Measurements of and correlations between block size and rock quality designation (RQD). Tunn Undergr Space Technol 20:362-377

Pells PJN (2004) On the absence of size effects for substance strength of Hawkesbury Sandstone. Aust Geomech 39:79-83

Pierce M, Cundall P, Potyondy D, Mas Ivars D (2007) A synthetic rock mass model for jointed rock. In: Rock mechanics: meeting society's challenges and demands, $1 \mathrm{st}$ Canada-US rock mechanics symposium, Vancouver, pp 341-349

Pierce M, Gaida M, DeGagne D (2009) Estimation of rock block strength. In: RockEng09, proceedings of the 3rd CANUS rock mechanics symposium, Toronto

Pratt HR, Black AD, Brown WS, Brace WF (1972) The effect of speciment size on the mechanical properties of unjointed diorite. Int J Rock Mech Min Sci 9(4):513-516

Price RH (1986) Effects of sample size on the mechanical behavior of Topopah Spring tuff. Sandia National Labs

Read J, Stacey P (2009) Guidelines for open pit slope design. CSIRO publishing, Clayton

Rosengren KJ, Jaeger JC (1968) The mechanical properties of an interlocked low-porosity aggregate. Geotechnique 18(3):317-326

Singh MM, Huck PJ (1972) Large scale triaxial tests on rock. In: The 14th US symposium on rock mechanics (USRMS). American Rock Mechanics Association

Smith A, Habte M (2011) A large-scale unconfined compressive strength test for determination of rock mass parameters in tunnel design. In: 14th Australasian tunnelling conference 2011: development of underground space. Engineers Australia and Australasian Institute of Mining and Metallurgy, pp 435

Stavrou A, Murphy W (2018) Quantifying the effects of scale and heterogeneity on the confined strength of micro-defected rocks. Int J Rock Mech Min Sci 102:131-143

Stavrou A, Vazaios I (2018) Investigating the effect of size and pre-existing microdefects on the strength and deformability of rock blocks. In: 2nd international discrete fracture network engineering conference. American Rock Mechanics Association 
Tsur-Lavie Y, Denekamp SA (1982) Comparison of size effect for different types of strength tests. Rock Mech 15(4):243-254

Turichshev A, Hadjigeorgiou J (2017) Quantifying the effects of vein mineralogy, thickness, and orientation on the strength of intact veined rock. Eng Geol 226:199-207

Vallejos JA, Suzuki K, Brzovic A, Ivars DM (2016) Application of synthetic rock mass modeling to veined core-size samples. Int J Rock Mech Min Sci 81:47-61

Vazaios I, Vlachopoulos N, Diederichs MS (2017) Integration of lidar-based structural input and discrete fracture network generation for underground applications. Geotech Geol Eng 35(5):2227-2251

Vazaios I, Farahmand K, Vlachopoulos N, Diederichs MS (2018) Effects of confinement on rock mass modulus: a synthetic rock mass modelling (SRM) study. J Rock Mech Geotech Eng 10(3):436-456
Weibull W (1939) A statistical theory of the strength of materials. Generalstabens litografiska anstalts förlag

Weibull W (1951) A statistical distribution function of wide applicability. J Appl Mech 18:293-297

Xu C, Dowd P (2010) A new computer code for discrete fracture network modelling. Comput Geosci 36:292-301

Yoshinaka R, Osada M, Park H, Sasaki T, Sasaki K (2008) Practical determination of mechanical design parameters of intact rock considering scale effect. Eng Geol 96(3-4):173-186

Zhang Q, Zhu H, Zhang L, Ding X (2011) Study of scale effect on intact rock strength using particle flow modeling. Int $\mathrm{J}$ Rock Mech Min Sci 48(8):1320-1328

Publisher's Note Springer Nature remains neutral with regard to jurisdictional claims in published maps and institutional affiliations. 